\title{
Polarized Proteins in Endothelium and Their Contribution to Function
}

\author{
Abigail G. Wolpe ${ }^{a, b}$ Claire A. Ruddiman ${ }^{a, c}$ Phillip J. Hall ${ }^{a}$ Brant E. Isakson ${ }^{a, d}$ \\ ${ }^{a}$ Robert M. Berne Cardiovascular Research Center, University of Virginia School of Medicine, Charlottesville, VA, \\ USA; ${ }^{b}$ Department of Cell Biology, University of Virginia School of Medicine, Charlottesville, VA, USA; ${ }^{c}$ Department \\ of Pharmacology, University of Virginia School of Medicine, Charlottesville, VA, USA; ${ }^{\mathrm{d}}$ Department of Molecular \\ Physiology and Biophysics, University of Virginia School of Medicine, Charlottesville, VA, USA
}

\section{Keywords}

Endothelium · Protein localization · Signaling domains ·

Arteriole

\begin{abstract}
Protein localization in endothelial cells is tightly regulated to create distinct signaling domains within their tight spatial restrictions including luminal membranes, abluminal membranes, and interendothelial junctions, as well as caveolae and calcium signaling domains. Protein localization in endothelial cells is also determined in part by the vascular bed, with differences between arteries and veins and between large and small arteries. Specific protein polarity and localization is essential for endothelial cells in responding to various extracellular stimuli. In this review, we examine protein localization in the endothelium of resistance arteries, with occasional references to other vessels for contrast, and how that polarization contributes to endothelial function and ultimately whole organism physiology. We highlight the protein localization on the luminal surface, discussing important physiological receptors and the glycocalyx. The protein polarization to the abluminal membrane is especially unique in small resistance arteries with the presence of the myoendothelial junction, a signaling microdomain that regulates vasodilation, feedback to smooth muscle cells, and ultimately total peripheral resistance. We also discuss the interendo-
\end{abstract}

karger@karger.com

(c) 2021 S. Karger AG, Basel

www.karger.com/jvi

Karger!" thelial junction, where tight junctions, adherens junctions, and gap junctions all convene and regulate endothelial function. Finally, we address planar cell polarity, or axial polarity, and how this is regulated by mechanosensory signals like blood flow.

(c) 2021 S. Karger AG, Basel

\section{Introduction}

Endothelium of resistance arteries is the key regulator of vasodilation, vascular permeability, inflammation, and immune signaling. The endothelium arguably sees some of the most dynamic stimuli from constant exposure to circulatory pressure and flow on the luminal side and direct cellular contact with smooth muscle cells on its basal side. Since these perturbations can be chemical, electrical, or mechanical in nature, protein localization and polarity must be clearly defined within the cell to manage accurate signal propagation among the diverse and numerous stimuli. This is a challenge in endothelium due to the squamous nature of the cells. Endothelial cell morphology is unique, flattened to be $<1 \mu \mathrm{m}$ thick with a protruding nuclear bulge [1]. Yet, the endothelium can remarkably polarize along 2

A.G.W. and C.A.R. contributed equally. 


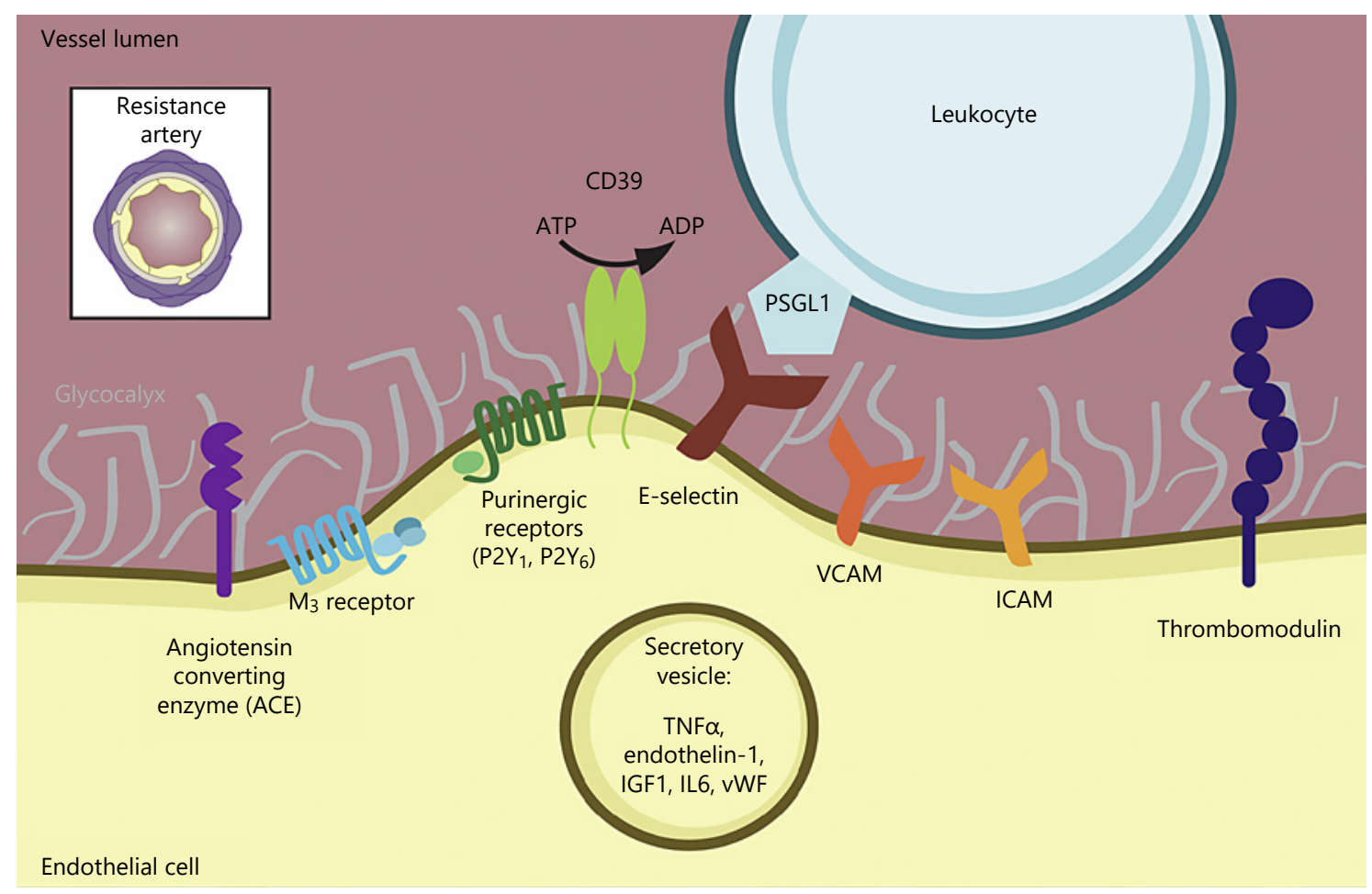

Fig. 1. Luminal protein localization in endothelium. The luminal membrane of the endothelium is in direct contact with the circulation. The glycocalyx, ectonucleases, immune signaling proteins, and luminally secreted proteins localize to the luminal membrane. Transverse view of resistance artery is depicted in the upper left for reference.

axes of the blood vessel [1]: apical-basal polarity aligns with the luminal-abluminal axis, while [2] planar cell polarity aligns with the longitudinal axis of the vessel. The goal of this review is to highlight the unique protein polarization between the luminal and abluminal membranes as well as the planar cell polarity of the endothelium and to provide insight on how this is regulated to control endothelial function. Although we focus on the endothelium of resistance arteries, comparisons to conduit and venous endothelium are used throughout and sometimes are necessary to highlight or extrapolate concepts.

\section{On the Face of Flow: Luminal Membrane}

Endothelial cells are positioned within an asymmetrical extracellular environment, where their apical membrane is exposed to the vessel lumen and in direct contact with the cells and factors of the blood, while the abluminal membrane is in close proximity to the overlaying vascular smooth muscle cells (VSMCs) and the internal elastic lamina (IEL), a specialized extracellular matrix (Fig. 1). It is important to note that due to the "flattened" endothelial morphology, the distance between the luminal and abluminal membranes of an endothelial cell can be as low as $200 \mathrm{~nm}[1,2]$. Despite this short distance, both the luminal and abluminal surfaces demonstrate unique protein localization and specialized functions. For instance, endothelial proteins involved in the inflammatory response, such as E-selectin, ICAM-1, and VCAM-1, are upregulated and localized to the luminal surface apropos for interacting with leukocytes in the circulation $[3,4]$. These proteins facilitate leukocyte adhesion, rolling, and transmigration involved in tissue infiltration. One might similarly expect a majority of endothelial signaling receptors and G-protein-coupled receptors (GPCRs) to be localized to their luminal face, to detect signaling ligands in the circulation; however, there is a dearth of evidence for the subcellular distribution of these receptors. In this section, we highlight the polarization of proteins to the luminal surface of endothelium and discuss where explicit localization studies are still needed. 


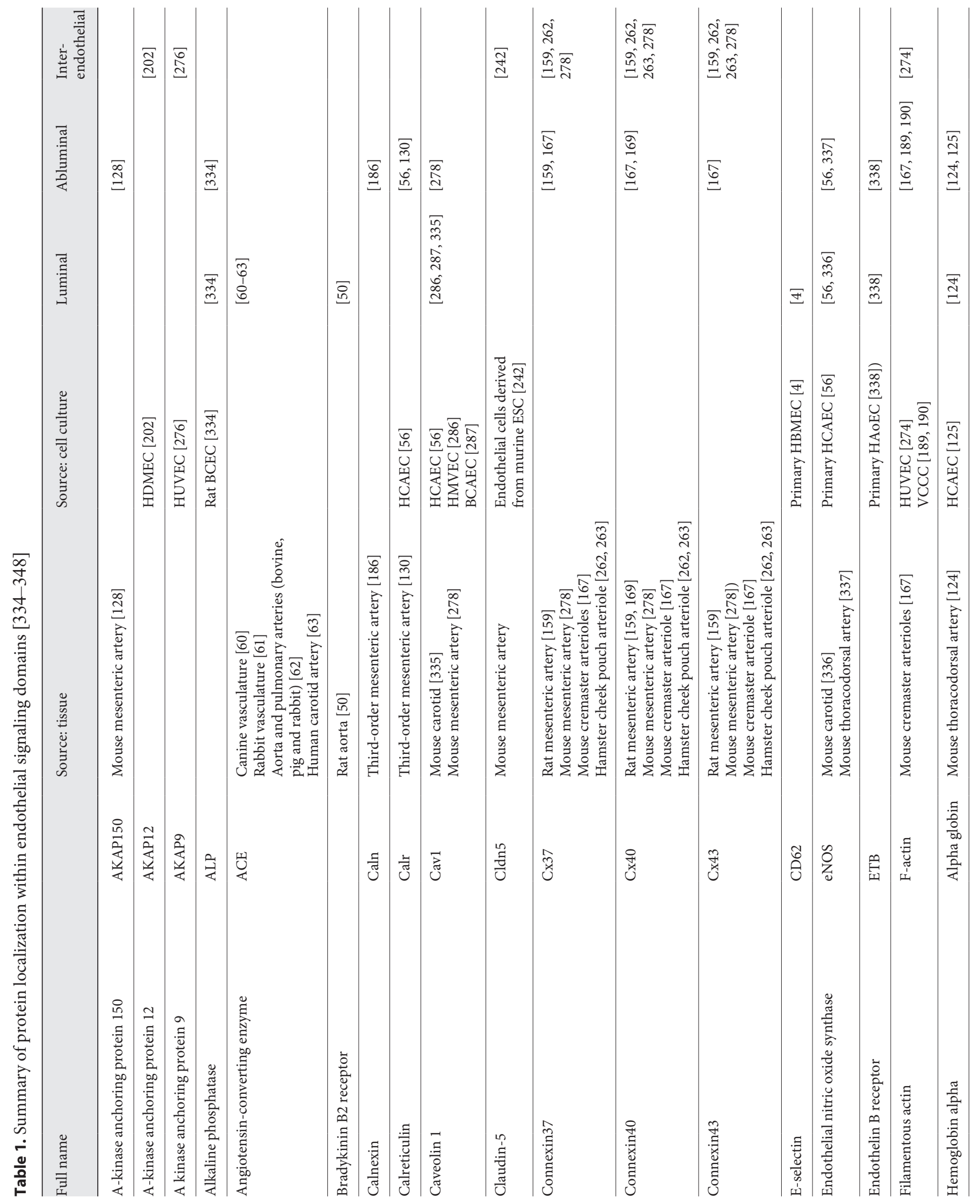




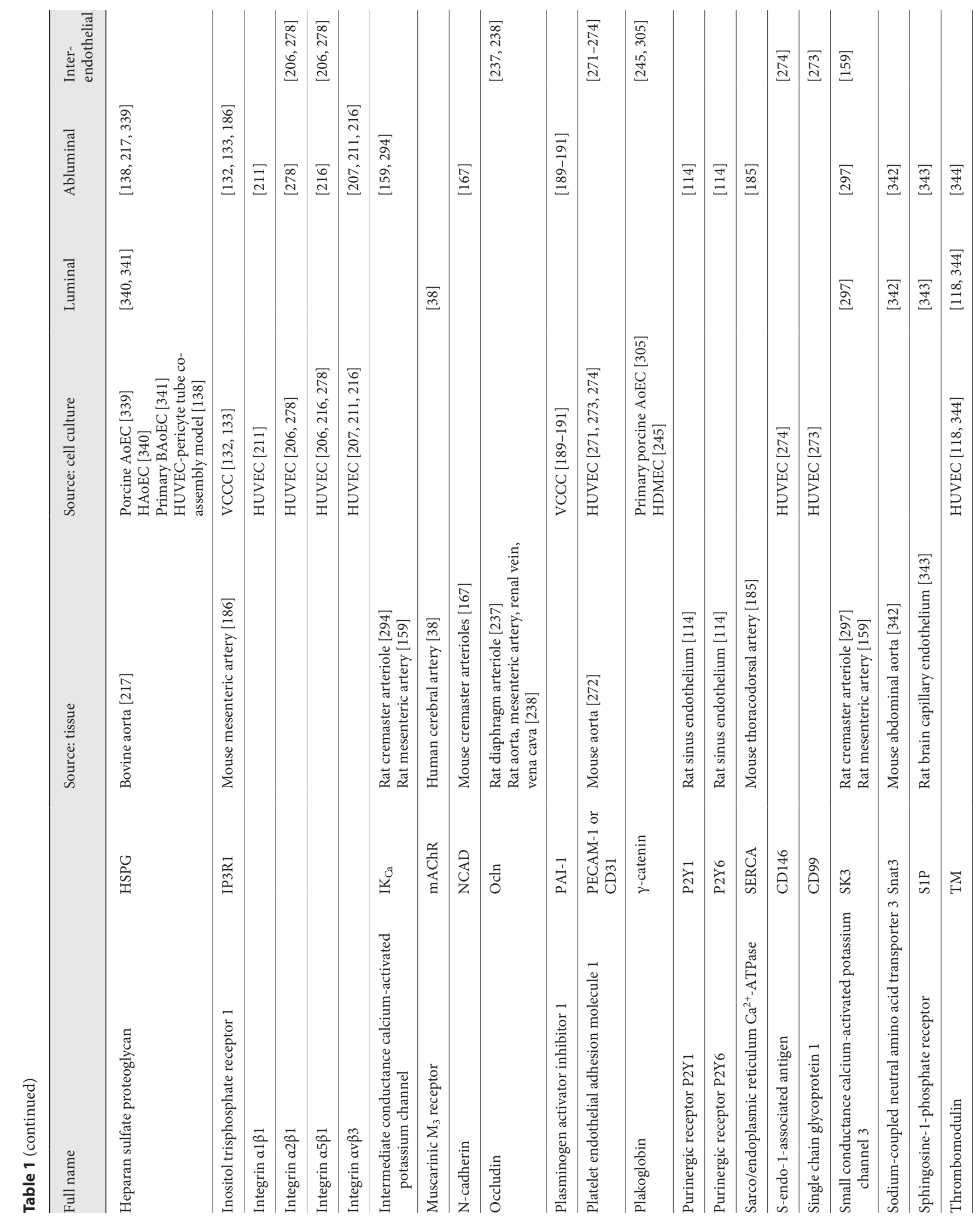




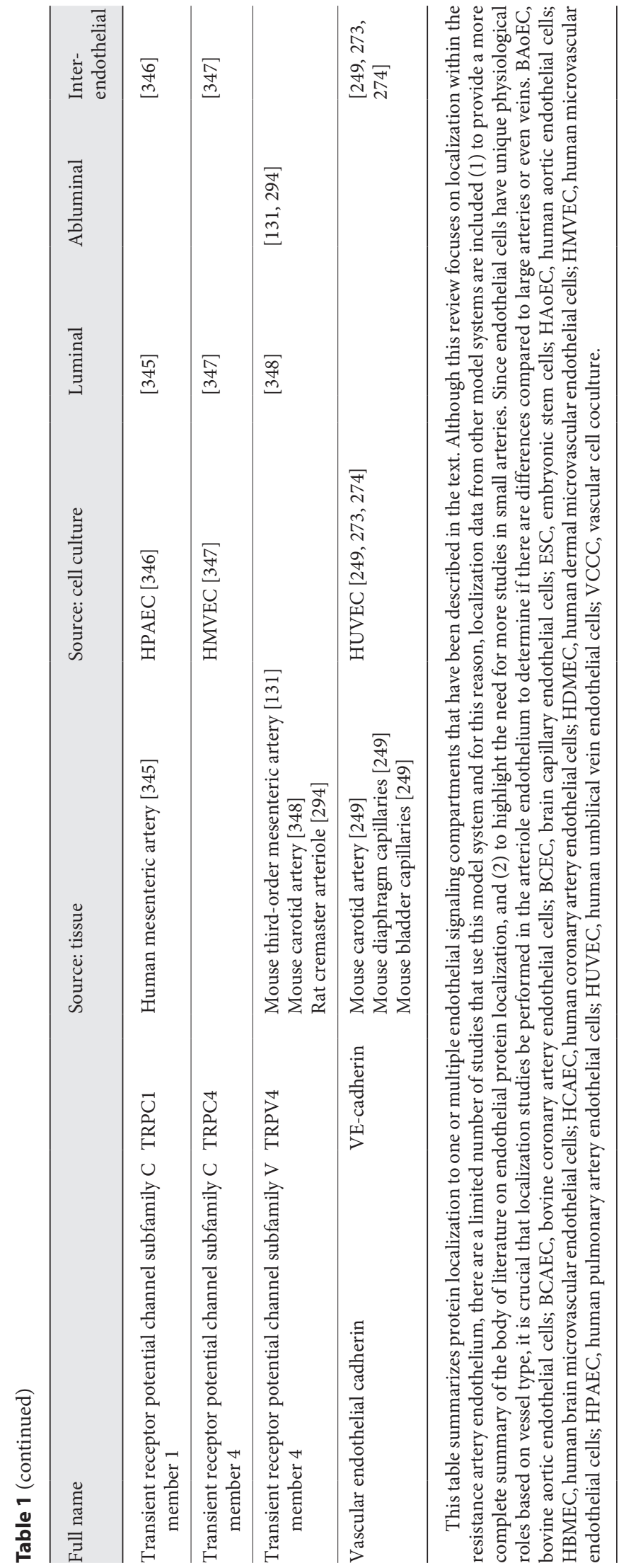

\section{Regulators of Endothelial Function on the Luminal Surface}

In this section, we will highlight some of the major regulators of vasodilation/vasoconstriction, coagulation, and inflammation pathways on the luminal endothelial surface of resistance arteries. Although we limit our discussion to peripheral arterioles, it should be noted that luminal/abluminal endothelial polarity has also been noted in the cerebral vasculature [5].

\section{Glycocalyx}

A hallmark example of this luminal/abluminal polarity is the glycocalyx, which is only present on the luminal side of the endothelium (shown in Fig. 1). It is composed of glycosaminoglycans, glycoproteins, and proteoglycans and is approximately $2-3 \mu \mathrm{m}$ thick in small arteries $[6,7]$. The glycocalyx facilitates the formation of luminal microdomains by providing a binding surface for circulating factors. Heparan sulfate proteoglycan (Table 1), a large proportion of the glycocalyx [8], bears a significant negative charge at physiological $\mathrm{pH}$, which ultimately promotes electrostatic interactions with positively charged residues on circulating proteins and factors [9]. The electrostatic force is adequate to initiate a stable interaction that can occur with various ligands $[9,10]$, and sequences for binding are often noncontiguous positively charged residues [10]. A major physiologically relevant group that binds to luminal heparan sulfate is anticoagulants, including antithrombin III [11], heparin cofactor II [12], and tissue factor pathway inhibitor [13]. The heparan sulfate-antithrombin interaction is one of the most well studied in the field and involves a rare 3-O-sulfation within a specific pentasaccharide on heparan sulfate, making antithrombin one of its most specific ligands [14-16]. The ability of these anticoagulants to interact with heparan sulfate at injury sites ensures the restoration of homeostasis rather than vessel-occluding thrombi. Circulating growth factors comprise another major group that binds to the glycocalyx, which include fibroblast growth factor (FGF) [17], transforming growth factor beta (TGF- $\beta$ ) [18], platelet-derived growth factor (PDGF) [19], hepatocyte growth factor [20], and vascular endothelial growth factor (VEGF) [21]. Heparan sulfate and heparin act as low-affinity receptors for FGF [22], and their interaction facilitates the dimerization of high-affinity receptors (FGFR1-4), leading to activation and induction of signaling $[23,24]$. While we have highlighted two major examples of how the glycocalyx facilitates luminal microdomain formation, there are 
numerous other circulating factors including enzymes, chemokines, and cytokines that bind to the glycocalyx $[9,25]$.

The glycocalyx is also instrumental in mechanotransduction. Its presence on the luminal surface regulates endothelial function by relaying changes in shear stress [2629]. A number of studies have investigated the role of the glycocalyx in nitric oxide (NO) production following exposure to shear stress. Specifically, when the glycocalyx is experimentally degraded, shear stress-induced NO production is reduced, thereby defining the glycocalyx as a regulator of this process [26-29]. This glycocalyx-mediated mechanotransduction may be physiologically more relevant for arterial endothelial cells, which experience higher shear stress compared to the venous endothelium [30-33]. In contrast, glycocalyx shedding may be more physiologically relevant in postcapillary venules than arterioles. The glycocalyx sheds in response to tumor necrosis factor alpha (TNF- $\alpha)[34,35]$, angiopoietin-2 [36], and matrix metalloproteinases [28], factors that are upregulated in cardiovascular disease and inflammation. This shedding helps expose the shorter leukocyte adhesion molecules that are also polarized to the luminal surface, such as P-selectin, in order to facilitate an inflammatory response, which canonically occurs in venules [37].

\section{Vasodilation/Vasoconstriction}

A crucial physiological homeostatic role of endothelial cells is the regulation of peripheral resistance through modulating vasodilation and vasoconstriction pathways. Many vasoactive signaling molecules are expressed on the luminal face of the endothelium, and thus, one could imagine that vasoactive receptors would be preferentially expressed on the luminal face of the endothelium in direct contact with vasoactive ligands in the blood. However, the subcellular localization of many vasoactive receptors has not yet been described in the endothelium. In this section, we discuss luminal localization for the receptors of acetylcholine (ACh), bradykinin, angiotensin, and epinephrine.

Muscarinic $\mathrm{M}_{3}$ receptors enriched on the luminal face of the endothelium $[38,39]$, where the vasoactive neurotransmitter $\mathrm{ACh}$ can bind and induce vasodilatory signaling in the arterial wall. However, due to the presence of cholinesterases in the plasma, circulating ACh is unlikely to act in an endocrine/paracrine manner and significantly contributes to the activation of muscarinic $\mathrm{M}_{3}$ receptors; rather, it appears the major source of vasoactive ACh is generated from microvascular endothelial cells, which express choline acetyltransferase and can re- lease $\mathrm{ACh}$ in an autocrine manner [40-45]. In resistance arteries, the elicited pathway is predominately endothelial-derived hyperpolarization (EDH), rather than NObased signaling [46-49].

Endothelial cell expression of the bradykinin GPCR $\mathrm{B}_{2}$ is enriched on the luminal face of the endothelium [50]. Bradykinin is a vasoactive substance that binds and activates $B_{2}$ to promote endothelial-dependent dilation [5154], by inhibiting adenylyl cyclase, activating PLC, and increasing endothelial intracellular $\mathrm{Ca}^{2+}$, which ultimately causes the release of NO and prostaglandins [55]. Bradykinin binding to $\mathrm{B}_{2}$ can also activate $\mathrm{EDH}$ in resistance arteries, although to a lesser extent $[47,52]$. In small arterioles, $\mathrm{B}_{2}$ is more highly expressed on SMCs rather than ECs, while larger arteries preferentially express $\mathrm{B}_{2}$ on ECs and not SMCs $[50,56]$. This expression pattern aligns with well-described dominance of NO-based vasodilation in conduit arteries compared to resistance arteries [46]. While $B_{2}$ receptors are widely expressed throughout the healthy endothelium [50], $B_{1}$ expression is limited to the endothelium of cerebral [57] and hepatic [58] microvessels. Its expression in homeostasis is minimal; however, it is induced following peripheral tissue injury [59], in the presence of the proinflammatory cytokine interferon gamma [57], or following Plasmodium chabaudi infection [58]. The resultant activation increases endothelial calcium activity and promotes inflammatory response.

The renin-angiotensin-aldosterone system is a critical player in regulating blood pressure homeostasis and involve vascular cells. Endothelial cells express angiotensinconverting enzyme (ACE) on their luminal surface, where it can readily generate the potent vasoconstrictor angiotensin II from circulating angiotensin I [60-63]. ACE is also implicated in the degradation of the circulating factor bradykinin, a process that also favors vasoconstriction, and is more highly expressed within arterioles compared to conduit arteries and veins in human samples [64]. However, the polarization of angiotensin II receptors within endothelial cells of resistance arteries is less clear. The receptors for angiotensin II, $\mathrm{AT}_{1} \mathrm{R}$ and $\mathrm{AT}_{2} \mathrm{R}$, are expressed on endothelial cells [65-67], but expression varies across species and vascular bed [67], and in resistance vessels, the expression may be regulated by angiotensin II itself [68]. While $\mathrm{AT}_{1} \mathrm{R}$ is most highly expressed in homeostatic conditions, $\mathrm{AT}_{2} \mathrm{R}$ is highly expressed during development [69], and its expression is induced by shear stress $[69,70]$ or following vascular injury [71-73]. Activation of endothelial $\mathrm{AT}_{1} \mathrm{R}$ and $\mathrm{AT}_{2} \mathrm{R}$ counteracts vasoconstriction responses elicited by $\mathrm{AT}_{1} \mathrm{R}$ activation on 
SMCs [67, 74-76], but the endothelial receptors also have roles in proliferation [77] and apoptosis [77, 78]. Many of the functional studies on endothelial AT receptor function focus on conduit arteries, such as the carotid $[74,76]$ or aorta $[70,72]$, while vessel AT receptor function is often studied in small resistance arteries $[79,80]$.

Circulating angiotensin II also stimulates the release of endothelin-1 [81, 82], an endogenous 21 -amino acid peptide that promotes vasoconstriction and is primarily produced by and stored within endothelial cells [83-85]. Its $\mathrm{ET}_{\mathrm{A}}$ receptor is found mainly on VSMCs, where binding of endothelin-1 induces the canonical vasoconstriction response; while its $\mathrm{ET}_{\mathrm{B}}$ receptor is mainly found on endothelial cells (and on VSMCs in large pulmonary arteries) [86], where it can promote vasodilation via $\mathrm{NO}$ and prostacyclin release $[87,88]$. Distribution of these receptors has been studied in the specialized vasculature of kidney [89], liver [90, 91], and lung [92, 93] via immunohistochemistry methods that demonstrate localization within the endothelium [94]. Despite this, a subcellular electron microscopy study was unable to detect $\mathrm{ET}_{\mathrm{B}}$ receptors in human coronary endothelial cells [95]; thus, there is limited information about polarization of $\mathrm{ET}_{\mathrm{B}}$ within endothelial cells (i.e., luminal vs. abluminal) or within the endothelium of peripheral resistance arteries.

Functional studies demonstrate that $\beta$-adrenergic receptors are expressed by the endothelium, in addition to their well-described role in VSMCs. The removal of endothelial cells in vitro, or denudation, attenuates the vasodilatory response to increasing doses of isoproterenol in both large [96] and small arteries [97], indicating that endothelial cells respond to $\beta$-adrenergic stimuli. However, there is little data available about the localization of endothelial $\beta$-adrenergic receptors. The $\beta_{2}$-adrenoceptor was reported to be predominantly expressed over the $\beta_{1^{-}}$ adrenoceptor in the internal mammary artery by autoradiography using $\left[{ }^{125} \mathrm{I}\right]$-cyanopinodolol-binding sites when incubated with ICI $118,551\left(\beta_{1}\right)$ or CGP 20712A $\left(\beta_{2}\right)$ [98]. However, this assay is insufficient to describe subcellular expression of the adrenoceptors in the endothelium. The $\beta_{2}$-adrenoceptor has been reported to localize to the cell surface of rat lung microvascular endothelial cells in vitro under basal conditions and shown to internalize in response to depletion of the GTPase Rab5a [99].

\section{Purinergic Signaling}

Purinergic signaling in the arterial vasculature is best known for its vasoconstrictive properties, though it is also associated with vasodilatory signaling [100]. In the kid- ney, adenosine infusion reduces single nephron glomerular filtration rate due to afferent arteriole vasoconstriction, likely induced by $\alpha 1$-adrenergic receptor activation [101]. Similarly, ATP released by perivascular nerves is generally thought to induce $\alpha$-adrenergic receptor-mediated smooth muscle constriction [102], though coronary arteries (250-500 $\mu \mathrm{m}$ diameter) isolated from lamb have been reported to dilate in response to ATP [103]. Recent work from our laboratory suggests that endothelial ATP, released through pannexin 1 (Panx1) channels, regulates cerebral myogenic tone. Endothelial-specific deletion of Panxl exhibited diminished myogenic tone, while smooth muscle-specific deletion of the channel had no effect on the generation of vessel tone [104].

However, in the systemic vasculature, endothelial purinergic signaling facilitates vasodilation. In cultured endothelial cells, the alpha subunit of ATP synthase localizes to the apical surface [105], which likely facilitates ATP release by ECs into the vessel lumen [106-109]. ATP can bind to purinergic receptors on the apical membrane, including $\mathrm{P}_{2} \mathrm{Y}_{1}$ and $\mathrm{P}_{2} \mathrm{Y}_{2}[110-112]$. Based on the autocrine signaling pathway and luminal release of ATP, these purinergic receptors may also be localized on the luminal surface of the endothelium $[102,113]$. However, immunohistochemistry on $\mathrm{P}_{2} \mathrm{Y}_{2}$ receptors in the intact endothelium of murine third-order mesenteric arteries demonstrates a punctate-like distribution pattern, and it is unclear if they localize to the luminal face [110]. Furthermore, an electron microscopy study on splenic endothelial cells demonstrates that $\mathrm{P}_{2} \mathrm{Y}_{1}$ and $\mathrm{P}_{2} \mathrm{Y}_{6}$ receptors localize to the abluminal surface [114]. Lastly, although the subcellular localization of $\mathrm{P}_{2} \mathrm{X}_{4}$ receptors, which bind ATP and its derivatives, has not been described in ECs, it is worth noting that they are expressed more highly in the human saphenous vein than in human mammary or radial artery [115], and $\mathrm{P} 2 \mathrm{X}_{4}$ deficiency in endothelial cells leads to a reduction in $\mathrm{NO}$ production and an increase in blood pressure [116]. Additional studies are needed to determine the polarization of purinergic receptors in resistance arteries.

\section{Coagulation}

A major endothelial function is balancing the injury repair mechanism of clotting to regulate the size of the repair. This requires the localization of anticoagulants to the site of clot formation. These anticoagulants primarily localize to the luminal face of the endothelium and are able to bind more effectively in lower flow environments like the microcirculation [117]. For instance, thrombomodulin is expressed on the endothelial luminal surface 
of arteries, veins, and lymphatics [118] and binds directly to thrombin to prevent its interaction with circulating procoagulant factors $[119,120]$. CD39, an ectonucleotidase of the E-NTDPase1 family, is localized to the luminal surface of the endothelium and reduces platelet aggregation through converting extracellular ATP to ADP [121, 122]. In pathogenic thrombosis, venous and arterial thrombi exhibit phenotypic differences, where venous thrombi contain more fibrin and arterial thrombi contain more platelets [123]. This suggests a mechanistic difference in the coagulation pathway across vessel type; however, it is likely due to differences in shear stress and flow rather than expression differences of coagulation mediators. For a summary of the polarized proteins on the luminal face of the endothelium see Figure 1.

\section{Abluminal Membrane}

Protein localization on the abluminal face of endothelial cells facilitates cell adhesion and heterocellular communication between ECs and SMCs. Here, we will examine proteins that are polarized to the abluminal compartment of the endothelium and highlight their roles within resistance arteries and impact on whole animal physiology.

\section{Internal Elastic Lamina}

In immediate contact with the abluminal endothelial surface is an extracellular matrix termed the IEL, which separates ECs from SMCs. The IEL of intact vessels, when viewed in cross section, is a wavy, dense layer situated between endothelium and smooth muscle $[124,125]$. In conduit arteries, laminae are also present between smooth muscle layers [46]. When viewed en face, the IEL of resistance arteries, but not conduit arteries, has a high proportion of fenestrations in the matrix separating the endothelium and SMCs $[46,124,126]$. Although it can vary by vascular bed, the fenestrations generally have a circular shape where extracellular matrix proteins are absent [46, $124,126,127]$. These fenestrations, often referred to as IEL holes, facilitate the heterocellular communication that is vital to regulating vasodilation and vasoconstriction pathways in resistance arteries, through allowing the formation of highly specific signaling microdomains called myoendothelial junctions (MEJs) [46, 56, 124, 128 134]. This layer also serves as an adhesion substrate for integrins that are localized to the endothelial abluminal surface, which participate in a number of important processes such as angiogenesis [135-137].
The IEL layer consists of collagen IV, elastin, lamin-8/10, nidogen, and heparan sulfate proteoglycans [138-142]; however, the composition is not uniform across vascular bed or vessel size [139, 141, 143, 144]. For example, conduit arteries, often referred to as elastic arteries due to their high elastin content, function to absorb the force generated by the heart $[141,144,145]$. Elastin in resistance arteries, although not as prevalent [144], still demonstrates important functionality in bearing longitudinal stress, rather than circumferential stress (as in conduits) $[139,140]$. In vitro work demonstrates secretion of other extracellular matrix proteins and suggests a collaborative effort between the endothelial and smooth muscle cells in forming the IEL $[138,146]$. For example, endothelial-derived extracellular matrix proteins include fibronectin [147] and elastin [148-150], while collagen I and III are secreted from the smooth muscle cell layer and are regulated by endothelial NO [151]. In injury or inflammation, additional matrix proteins such as fibrinogen and fibronectin are secreted $[152,153]$. However, it is unclear whether these proteins identified in vitro are deposited in the IEL of intact vessels, become part of the adventitia, or are released into the circulation. For example, collagen $I$ is more prevalent in the adventitia rather than in the IEL of cremaster arterioles [139].

\section{Myoendothelial Junctions}

MEJs, also referred to as myoendothelial projections or myoendothelial gap junctions, are an anatomical hallmark of resistance arteries. The junction, first identified in Rhodin's electron microscopy ultrastructural analysis of small arteries [154], is formed through a club-like endothelial extension through the aforementioned IEL fenestrations, in which ECs can directly contact and communicate with the overlaying SMC $[124,125,132,155$, 156]. Although rare, instances of SMC projections through the IEL have also been reported [157]. The MEJs are considered signaling microdomains due to the localization of many signaling molecules involved in heterocellular communication; thus, a large portion of abluminal protein polarization occurs in these distinct regions. It is hypothesized that the unique protein localization that occurs at MEJs facilitates EDH, the dominant vasodilatory signaling mechanism in resistance arterioles [46-49, $134,158]$. Key players of EDH that localize to the MEJ include transient receptor potential vanilloid 4 (TRPV4), calcium-activated intermediate conductance potassium $\left(\mathrm{IK}_{\mathrm{Ca}}\right)$ channels, and hemoglobin alpha (Fig. 2). TRPV4 channels facilitate calcium influx at the MEJ $[128,131]$, leading to $\mathrm{IK}_{\mathrm{Ca}}$ channel activation [159]. The efflux of po- 


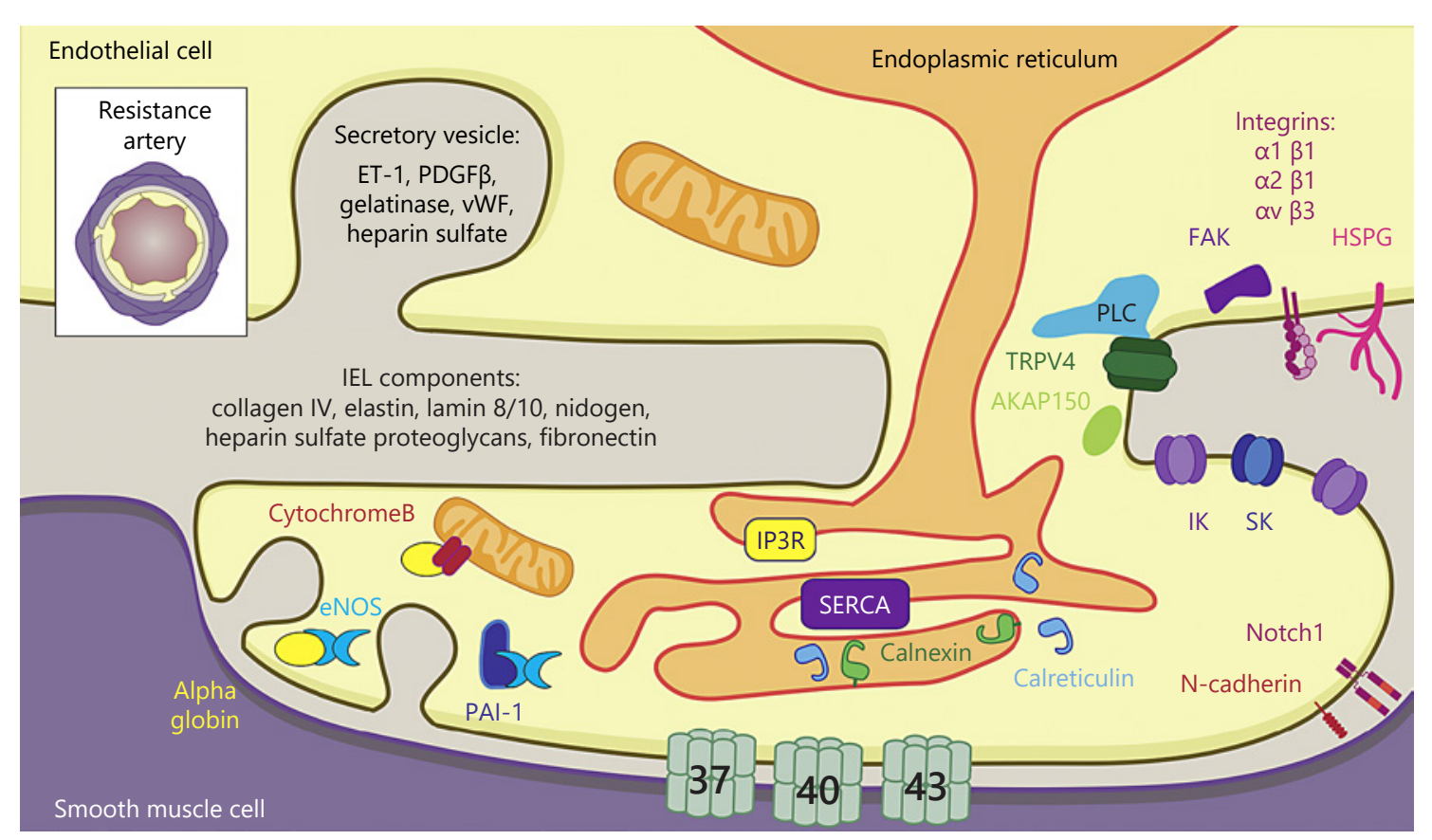

Fig. 2. Abluminal protein localization in endothelium. The abluminal membrane of the endothelium is in direct contact with the extracellular matrix, and sporadically with the smooth muscle in small arteries. Transverse view of resistance artery is depicted in the upper left for reference.

tassium ions hyperpolarizes SMCs, and this results in vasodilation [160]. Inward rectifying channels are also an essential mechanism, whereby endothelial cells conduct hyperpolarization and thus vasodilation in systemic and cerebral arteries [161-163]. While their expression has been implicated in the MEJ, their precise subcellular localization in the endothelium is not currently known. Understanding the localization of inwardly rectifying potassium channels could be helpful in deciphering its functional relationship with other ion channels or gap junctions [164].

Specialized localization to the MEJ can alter how protein activation effects cellular physiology. Calcium-activated small conductance potassium $\mathrm{SK}_{\mathrm{Ca}}$ channels have been observed at the MEJ, though they are primarily localized to interendothelial junctions [159]. The distribution of $\mathrm{SK}_{\mathrm{Ca}}$ in endothelium may indicate the channels participation in distinct signaling pathways. The $\mathrm{SK}_{\mathrm{Ca}}$ localized to the MEJ likely participates in $\operatorname{EDH}[165,166]$, whereas $\mathrm{SK}_{\mathrm{Ca}}$ channels present at interendothelial junctions may be better positioned to activate endothelial nitric oxide synthase (eNOS) localized in luminal caveolae or on the Golgi and generate NO for luminal release. Independent calcium events are likely required to activate both pools of $\mathrm{SK}_{\mathrm{Ca}}$ channels, further illustrating how localization can dictate function.

Connexins are enriched at the MEJ and also regulate vasodilation and vasoconstriction pathways. In small arterioles, connexin 37, 40, and 43 are most prevalent (Cx37, $\mathrm{Cx} 40$, and $\mathrm{Cx} 43$, respectively) $[159,167]$, with $\mathrm{Cx} 40 \mathrm{ex}-$ hibiting arterial specificity in mice [168]. Although connexins are enriched at the MEJ, they are also found at the interendothelial junction (Table 1). When assembled as hexamers, connexins form gap junctions that physically link the cytoplasm of 2 cells. Heterocellular communication occurs through these gap junctions to facilitate EDH [169] and myoendothelial feedback [132, 170, 171]. Myoendothelial feedback is critical in regulating the degree of constriction elicited through $\alpha$-adrenergic activation on VSMCs. This feedback occurs when the inositol 1,4,5-trisphosphate $\left(\mathrm{IP}_{3}\right)$ generated in VSMC diffuses through myoendothelial gap junctions, where it then activates vasodilatory signaling in ECs as negative feedback regulation [132, 172-176]. Myoendothelial feedback can also occur when calcium from smooth muscle cells transverses the gap junctions to induce vasodilatory signaling in endothelial cells $[132,177]$. When $\mathrm{Cx} 40$ gap junctions are blocked by loading inhibitory antibodies, this negative 
regulation is lost, illustrating the functional importance of gap junctions within this microdomain [169]. Thus, the localization of gap junctions to the abluminal surface of the endothelium, and within the MEJ signaling microdomains, is essential in modulating vasodilatory signaling [46].

While EDH-mediated vasodilation is dominant in resistance arteries, NO still contributes to vasodilatory signaling within these vessels $[124,125,178,179]$. Since NO has such a short half-life [180], enrichment of eNOS to MEJ allows for quick diffusion of NO to the VSMC membrane, where it activates vasodilation. Our laboratory has shown that eNOS activation at MEJ is differentially activated compared to eNOS elsewhere in the endothelium, creating 2 functionally distinct pools of eNOS (Table 1) [56]. This is likely a result of eNOS-lipid interactions at the MEJ microdomain and another example of how protein localization to microdomains impacts its function [56]. Regulators of eNOS, including hemoglobin alpha, CYB5R3, plasminogen activator inhibitor 1, and caveolin-1, also localize to the MEJ [124, 125, 181-183]. Hemoglobin alpha, a protein specifically expressed in the resistance artery endothelium [125], is also enriched within the MEJ, where it regulates eNOS $[124,125]$ and may influence the dominance of EDH-based vasodilation in these vessels [46]. (For an extensive review on the function of NO in endothelial cells, refer to Leo et al. [184].)

As discussed at length in this section, calcium signaling at the MEJ is crucial for regulating the extent of vasodilation and vasoconstriction. It follows that the endoplasmic reticulum (ER), a major source of intracellular calcium, is enriched within MEJ microdomains, as identified via electron microscopy in both hamster mesenteric arteries and mouse cremaster arterioles [132, 156]. Several studies have also demonstrated the presence of ERassociated proteins within these restricted areas $[130,133$, 185]. Specifically, inositol trisphosphate receptor $\left(\mathrm{IP}_{3} \mathrm{R}\right)$ 1 [133], calreticulin [56, 125, 130], SERCA [185], and calnexin [186] have all been identified within IEL holes. Calreticulin, canonical marker of the ER lumen [187], localizes to $80 \%$ of the IEL holes in resistance arteries, but influences heterocellular communication in an ER-independent manner [130]. Each ER marker appears to have its own level of occupancy within the IEL holes (not all studies cited include quantification) [130]. A future study that quantifies each respective ER marker may help us better understand the role of ER localization at the MEJ. Recent work has illustrated that mitochondria are also present in the MEJ and may dictate the localization of calcium events in the MEJ [188]. The presence of these organelles in this abluminally-situated signaling microdomain is an example of spatial optimization that allows a rapid vasodilation response following ER calcium release.

In summary, the MEJ is a microdomain within resistance arteries where signaling occurs to regulate vasodilation and ultimately total peripheral resistance. In this section, we discussed the following proteins localized MEJ: TRPV4, IK $\mathrm{Ca}$, hemoglobin alpha, CYB5R3, caveolin-1, Cx37, Cx40, Cx43, eNOS, inositol trisphosphate receptor 1 , calreticulin, SERCA, and calnexin. In the next section, we also discuss A-kinase anchoring proteins (AKAPs) at the MEJ. Although not discussed at length here, it should be noted that a number of other proteins have also been identified at the MEJ: N-cadherin [167], F-actin [167, 189, 190], desmin [167], plasminogen activator inhibitor 1 [189-191], serpin-binding protein-1 [190], staufen [190], nicotinamide phosphoribosyl transferase [190], Notch 1 [191], Notch 2 [191], Notch 3 [191], and Jagged 1 [191]. Although protein localization at the MEJ and the resulting functional consequences are well studied, only a few studies have examined their formation mechanism $[46,189,190]$, and much remains to be discovered regarding their temporal dynamics and spatial organization within the arterial wall.

\section{A-Kinase Anchoring Proteins (AKAPs)}

AKAPs primarily function as scaffolds to create microsignaling complexes within cells that allow for specific intentional kinase activity while avoiding indiscriminate phosphorylation [192]. This protein family consists of 60 isoforms [193] and is defined by a 14-18-residue helix that interacts with protein kinase A (PKA) [194]; however, AKAPs have been shown to bind to other enzymes such as protein kinase C (PKC) [195, 196]. Within the resistance arteries, AKAPs regulate both vasodilation and vasoconstriction pathways. Murine AKAP150, also known as bovine AKAP5 or human AKAP75 [197], binds and localizes PKC to MEJs within the resistance artery wall, thus demonstrating abluminal localization [128]. This allows PKC-dependent activation of TRPV4 channels and promotes EDH-mediated vasodilation [128]. AKAP1 is expressed on the cytoplasmic face of mitochondria in endothelial cells rather than the MEJ [198], and resistance arteries from global knockout mice exhibit reduced vasodilation to ACh [198]. These studies demonstrate how AKAPs can regulate vasodilation pathways. While outside the scope of this review, it should be noted that AKAPs also form microsignaling complexes in vascular smooth muscle cells and regulate vasoconstriction 
[199-201]. Last, these anchoring proteins also localize to the interendothelial junction (Table 1) to modulate endothelial barrier function $[202,203]$. Upon disrupting PKA's interaction with AKAP12 or AKAP220, endothelial barrier function is reduced [202]. Further, when AKAP12 is depleted from zebrafish embryos, interendothelial junction integrity is reduced, resulting in hemorrhage [203]. For an extensive review on AKAPs in the cardiovascular system, please see reference [201].

\section{Integrins on the Abluminal Face}

Integrins are membrane-associated glycoproteins composed of $\alpha$ - and $\beta$-subunits, and they are most well studied in the context of angiogenesis, development, and wound healing when their expression is upregulated [136, $204,205]$. This section of the review will focus on their function in healthy adult arteries, wherein they regulate interendothelial adhesion and mechanotransduction $[135,206]$. Integrins are capable of binding extracellular matrix components found in the IEL $[135,136]$, suggesting localization to the abluminal face of the endothelial cells [207]; however, explicit localization studies of integrins in healthy adult endothelium are limited. While most integrin subunits are thought to be evenly distributed throughout the arterial and venous endothelium, integrin subunit $\beta 4$ is expressed predominantly in arterioles [208]. Primary human corneal endothelial cells have been shown to express 12 of the 18 a-subtypes (ITGA1, ITGA2, ITGA3, ITGA4, ITGA5, ITGA6, ITGA7, ITGA10, ITGA11, ITGAE, ITGA $V$, and ITGAL) and 6 of the $8 \beta$-subtypes (ITGB1, ITGB3, ITGB4, ITGB5, ITGB7, and ITGBL1) $[209,210]$. While integrin heterodimer protein expression and distribution in endothelial cells is not well understood in vivo, many studies have focused on the contributions of individual heterodimers. Integrins $\alpha 2 \beta 1$ and a1 $\beta 1$ facilitate endothelial binding to collagen IV, a major extracellular matrix protein in the IEL [211]. Fibrinogen and fibronectin have similarly been shown to bind $\alpha v \beta 3$ and $\alpha 5 \beta 1$, respectively $[207,211]$. These suggest a localization of these heterodimers to the abluminal face of the endothelium (Fig. 1); however, integrins $\alpha 2 \beta 1$ and $\alpha 5 \beta 1$ have been described to preferentially localize to interendothelial junctions rather than the abluminal membrane [211].

Focal adhesion complexes, where integrins convert mechanical stimuli to molecular pathways through outside-in signaling paradigms [212], are also restricted to the abluminal cell-matrix interface. Focal adhesion kinase, a non-receptor tyrosine kinase, is recruited to focal adhesions in ECs under flow conditions and facilitates integrin signaling cascades $[213,214]$. The upregulation of fibronectin in the arterial extracellular matrix, which largely occurs during angiogenesis [137] and atherosclerosis [215], is known to drive the formation of focal adhesion plaques that are enriched with integrins $\alpha v \beta 3$ and a5 $\beta 1$ [216]. Heparan sulfate proteoglycans also localize to the abluminal membrane (Table 1 ) and are implicated in focal adhesion formation [217]. While it is known that this interaction is necessary for mechanosensation [218] and directional migration [219], the individual contribution of each integrin heterodimer had not been understood. Recent work using peptidomimetics designed to specifically and individually antagonize each heterodimer demonstrated that binding of extracellular substrates and subsequent activation of integrin $\alpha 5 \beta 1$ lead to rapid recruitment of $\alpha v \beta 3$ at focal adhesions [216]. Substrateinduced focal adhesion formation and the resulting cell spreading each require the recruitment, but not activation, of integrin $\alpha v \beta 3$ [216]. This interaction demonstrates how the dynamic localization of endothelial integrins at the abluminal membrane can dictate cellular function.

\section{Abluminal/Luminal Polarity of the Endothelial Secretome}

Endothelial protein polarization goes beyond just cell surface expression; it also applies to protein and molecular secretion patterns. The endothelium comprises one of the largest secretory organs [220], and accordingly, it regulates the release of proteins and molecules to its luminal or abluminal face over its thickness of just $200 \mathrm{~nm}$ (Fig. 2) $[2,221]$. Protein secretion has been studied in the context of varying environmental stimuli, including shear stress $[222,223]$, proangiogenic stimuli $[224,225]$, or proinflammatory $[224,225]$ stimuli; however, the explicit emphasis on its polarization is more recent [221]. Most secreted factors $(90 \%)$ from endothelial cells are released to the luminal surface [221] and are often carried via extracellular vesicles [221]. These include TNF- $\alpha$ [221], IL-6 [221], IGF-1 [221], soluble ACE2 [226], and ATP [106, $107,109]$. Extracellular matrix proteins comprise the majority of proteins secreted abluminally, but also include endothelin-1, PDGF- $\beta$, cell adhesion molecules, and calcium-binding proteins [221, 227]. Surprisingly, extracellular matrix proteins can also be secreted luminally, although these likely represent regulators and turnover [221]. Other proteins and enzymes that are secreted in the abluminal direction include gelatinases [147], tissue in- 


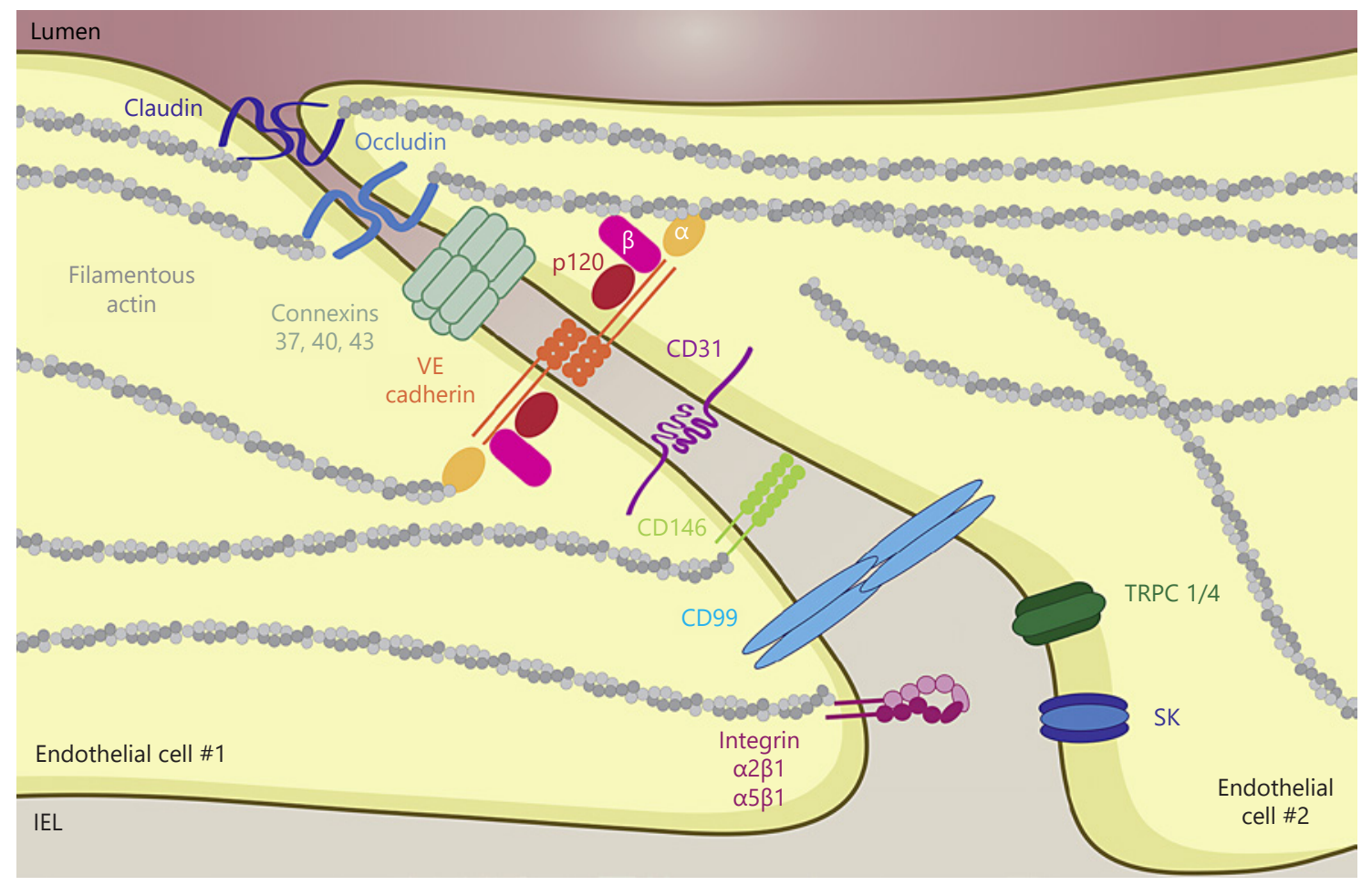

Fig. 3. Interendothelial junction protein localization in endothelium. The apposition of endothelium is a key area of protein localization.

hibitor of metalloproteinases [147], and PDGF [221, 227]. These secreted factors released abluminally may reach the smooth muscle or stay within the IEL, and the permeability of the IEL may in part determine their final destination [228]. A number of other factors are described to be secreted in both directions, exhibiting intentional activity in each direction, including Von Willebrand factor [221, 223, 229], heparan sulfate [230], and endothelin-1 [221, 231-233]. Despite canonical differences in arterial and venous endothelium, the secretome polarization is largely comparable between the arterial and venous endothelial cell cultures [221]. Any secretome differences across vessel type are likely related to individual vessel function, although studies focusing on differential secretion are limited [221, 223, 234].

In summary, the endothelial luminal face is primed to interact with cells in the blood through secretions or direct interactions and is exposed to hemodynamic forces, while the abluminal face is largely in contact with the IEL, except when endothelial cells come into direct contact with SMC at MEJs in resistance arterioles. Both the luminal and abluminal faces of the endothelium have been specialized by and for the microenvironment they exist in and facilitate directed signaling and function. A summary of our discussion on endothelial abluminal protein polarization is given in Figure 2.

\section{Holding Us All Together: Interendothelial Junctions}

Interendothelial junctions connect adjacent endothelial cells and broadly consist of adherens junctions, tight junctions, and gap junctions $[235,236]$. The planar polarity of protein localization to interendothelial junctions allows the endothelium to be an active and selective manager in maintaining circulatory volume and directing stimuli-induced permeability. Thus, the proteins localized to interendothelial junctions are an example of the functional importance of protein polarization in endothelium.

Tight junctions are composed of claudins, occludins, and junctional adhesion molecules (Fig. 3), and they are highly organized in arteries compared to veins (Fig. 4) $[237,238]$. Tight junctions tend to form more toward the luminal surface compared to the adherens junctions, which tend to seal endothelial borders near the abluminal 

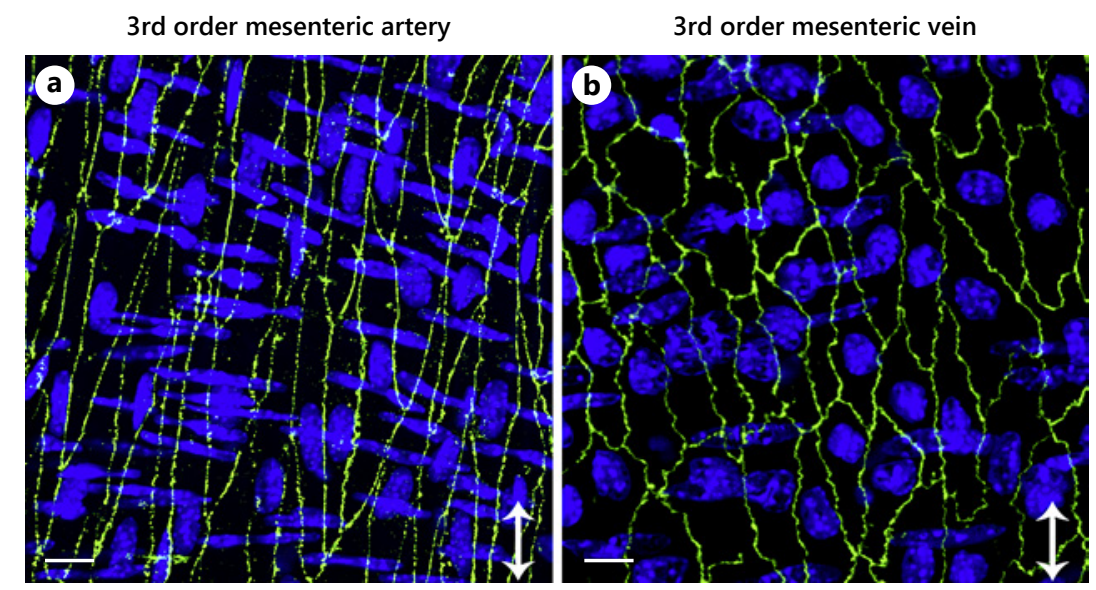

Fig. 4. Polarization of endothelium in response to different flow environments. Claudin-5 (green, Thermo Fisher 34-1600) is used to demonstrate differences in polarization of interendothelial proteins to lateral edges of the cells in a murine third-order mesenteric artery with high flow (a) compared with a murine third-order mesenteric vein with low flow (b). The images also highlight endothelial morphological differences in arteries versus veins: arte- rial endothelial cells are elongated in the direction of flow, while venous endothelial cells are more rectangular in shape and resemble cultured cells. For each image, arrow indicates direction of flow, scale bar is $10 \mu \mathrm{m}$, and nuclei are shown in blue, with endothelial nuclei oriented vertically and SMC nuclei oriented horizontally. Images were obtained with a Zeiss 880 LSM Airyscan module ( $\times 40$ oil objective) and are shown as $Z$-projections. face [236]. More apical localization allows tight junctions to tightly regulate paracellular transport, and an enrichment of these junctions in cerebral arteries in part explains the strong blood-brain barrier [239]. In small arterioles, tight junctions are continuous and highly organized, while small venules have discontinuous tight junctions, consisting of short segments that can be arranged either perpendicularly or parallel to the interendothelial junction, leading to gaps between ECs [237]. This description of venule tight junctions is similar to the organization of adherens junctions described in human umbilical venous endothelial cells under static culture conditions [240]. Last, in capillaries, these junctions are also loosely organized, and often times the capillary endothelium is fenestrated, where endothelial cells are not continuously connected via interendothelial junctions $[237,238]$. The differential organization of tight junctions across vessel type reflects their respective roles in fluid and solute transport; however, it should be noted that several other factors contribute to vessel permeability including glycocalyx composition and inflammatory cytokines [241].

Adherens junctions also localize to the endothelial cell-cell junctions and can actually direct the organization of tight junctions $[236,242]$. The main protein in adherens junctions is cadherin, specifically vascular endothe- lial (VE)-cadherin in endothelial cells, which is ultimately connected to the actin cytoskeleton through scaffolding proteins such as $\alpha$-catenin, $\alpha$-actinin, $\beta$-catenin, $p 120$, and plakoglobin (shown in Fig. 3) [243-246]. While Ncadherin expression is similar to VE-cadherin in endothelial cells, it does not demonstrate polarization to the interendothelial junction $[247,248]$. There are no reported differences in the general assembly of adherens junctions between vessel types; however, an important arteriovenous difference is the phosphorylation state of VEcadherin [249]. In vivo, arterial endothelial cells do not have phosphorylated VE-cadherin, whereas capillary and venous endothelial cells have constitutively phosphorylated VE-cadherin, making their ECs more susceptible to bradykinin-induced permeability [249]. This phosphorylation is regulated by low shear stress, which reflects the physiological levels reported for veins [32, 249, 250]. Furthermore, vascular endothelial cell-specific phosphotyrosine phosphatase is more enriched within arterial endothelial cells [251, 252] and binds to VE-cadherin [253]. However, to our knowledge, there are no studies that directly demonstrate polarization of vascular endothelial cell-specific phosphotyrosine phosphatase to the interendothelial junction with immunohistochemical or electron microscopy experiments. The polarization of VEcadherin and the associated scaffolding proteins to the 
interendothelial junction allows the endothelium to dynamically respond to stimuli, such as VEGF $[254,255]$.

In addition to tight and adherens junctions, gap junctions demonstrate polarized expression, where they have been described to alternate with tight junctions [237, 256]. Gap junctions are formed when 2 connexons (hexamers of connexin proteins) come together to join the cytoplasm of 2 neighboring cells. Endothelial connexins that localize to the interendothelial junction include $\mathrm{Cx} 37$ $[159,257], C x 40[168,258-261]$, and $C x 43$ [262]. In resistance arteries, $\mathrm{Cx} 43, \mathrm{Cx} 40$, and $\mathrm{Cx} 37$ demonstrate localization to the interendothelial junction and MEJs (Table 1) $[159,167,263]$. However, connexins are differentially expressed across the vasculature and can vary across species [257, 264-267]. In hamster arterioles, Cx43 is present at the interendothelial junction [262], while $\mathrm{Cx} 43$ is generally not detectable in aortic murine endothelium, except for areas of disturbed flow [257, 266, 267]. In mice, Cx40 is specific for endothelial cells in arteries and not present in smooth muscle cells [168, 258-260], and regulates vasodilation $[259,260,268]$. At the ultrastructural level, gap junctions have not been detected in small venules [237]; however, valves in small venules demonstrate specific interendothelial expression of $\mathrm{Cx} 37$ and $\mathrm{Cx} 43$ via immunohistochemistry [269]. These connexins are also differentially expressed throughout the venous vasculature [269]. While outside the scope of this review, it is worth noting that venous valves are an interesting vascular hallmark that exhibits specialized protein localization [269]. The intentional spatial localization of gap junctions within resistance arteries (Table 1) allows for controlled and directed communication within the vascular wall, which is another example of how protein polarization is imperative in maintaining homeostasis. For an extensive review on vascular connexins, we suggest reference [270].

Numerous other proteins also exhibit polarized expression along endothelial cell-cell contacts outside of the well-established tight, adherens, and gap junctions. A great example is platelet endothelial adhesion molecule 1 (PECAM-1, also known as CD31), which localizes to these interendothelial junctions, independent of tight or adherens junctions, and is required for leukocyte transmigration [271, 272]. Similarly, CD99 is also localized to the lateral edges of the endothelial cells and facilitates monocyte transmigration [273]. S-endo-1-associated antigen, or CD146, is expressed at interendothelial junctions and regulates paracellular permeability; however, it is also expressed on the apical membrane of cultured endothelial cells (Table 1) [274]. In addition to their ablu- minal polarization, integrins, specifically $\alpha 2 \beta 1$ and $\alpha 5 \beta 1$ heterodimers, are highly expressed at the interendothelial junction (Table 1) and regulate endothelial barrier function $[211,275]$. Last, Akap9 may localize with integrins at the interendothelial junctions to mediate vascular permeability [276]. Figure 3 summarizes our discussion above.

\section{Other Realms of the Endothelium}

While the localization of many endothelial proteins can be characterized as luminal, abluminal, or interendothelial, others are dynamic or occur at multiple sites in the cell. Caveolae create signaling microdomains through invaginations in the membrane, which are integral for vasoactive signaling and normal lipid transport. These membrane invaginations have been observed on both faces of the endothelium. Similarly, distinct endothelial calcium signals can occur at ER-plasma membrane contacts and at the MEJ, with very different physiological effects. Last, many proteins exhibit variable localization patterns, which are dictated by the rate and direction of blood flow.

\section{Caveolae: The Microdomain Makers}

Lipid rafts help facilitate microdomain formation. A subset of lipid rafts is caveolae, which are found in numerous cell types, including epithelial cells, adipocytes, fibroblasts, vascular SMC, and endothelial cells [277]. In endothelial cells, caveolae are enriched within the MEJ [278], although they also demonstrate luminal localization (Table 1). These membrane microvesicles are uniquely coated with one of the 3 members of the caveolin protein family, caveolin-1, -2 , or -3 [279]. Numerous proteins have been shown to localize to endothelial caveolae including several already discussed within this review: bradykinin receptor $\mathrm{B}_{2},[280]$ muscarinic $\mathrm{M}_{3}$ receptor [281], P2Y1 [114], and eNOS [282].

Caveolae are required for normal transcytosis of lipoproteins into endothelial cells. In an $\mathrm{ApoE}^{-/-}$background, global deletion of caveolin-1 reduced LDL infiltration of the aortic wall, while EC-specific reexpression of caveolin-1 rescued LDL [283]. In human microvascular endothelial cells in culture, immunocytochemistry demonstrated that caveolin-1 colocalizes with ALK-1, which has also be implicated in LDL transcytosis [284]. The class B, type I scavenger receptor, SR-BI, a well-described HDL 
receptor, has been shown to cofractionate and preferentially colocalize with caveolin-1 in CHO cells [285], further suggesting that caveolae are integral to lipoprotein transport in many cell types, though this observation has yet to be confirmed in endothelial cells.

Proteins that are enriched within the MEJ have been shown to interact with Cav1, such as TRPV4 channels [286, 287], $\mathrm{IP}_{3}$ Rs [278], and $\mathrm{Cx} 43$ [278]. Further, Cav1 may localize AKAP150 to the MEJ [128]. The localization of Cav1 to MEJ may have important functional consequences, as Cav1 depletion demonstrates impaired vasodilation [278, 286, 287]. Cav1 negatively regulates eNOS at the MEJ, thereby facilitating 2 functionally distinct pools of eNOS within the endothelium [56]. Its association with eNOS physically prevents the binding of calmodulin, thereby preventing eNOS activation and NO production [282]. This interaction may contribute to the dominance of $\mathrm{EDH}$ in small arteries and is discussed more in the following section [278].

\section{Spot the Spark: Mapping Calcium Signaling Microdomains}

As a second messenger with a role in many signaling cascades, the response triggered by a calcium event is determined in part by its subcellular localization. Endothelial calcium events occur in spatially restricted microdomains, such as caveolae on the plasma membrane and the MEJ. Intracellular calcium signaling is of particular importance due to its role regulating endothelial generation of vasoactive factors either through the production of soluble factors (NO and COX) or through membrane hyperpolarization. This section will focus on the localization of different calcium signaling microdomains; however, we recommend the recent review by Ottolini et al. [288] for discussion of calcium dynamics in the vasculature.

\section{$I P_{3} R$-Mediated Release of Stored Calcium}

Sites of stored calcium release must also be precisely regulated in the endothelium. Inositol 1,4,5-trisphosphate receptors $\left(\mathrm{IP}_{3} \mathrm{R}\right)$ are a family of ER calcium channels, which in mammals consist of 3 subtypes $\left(\mathrm{IP}_{3} \mathrm{R} 1\right.$, $\mathrm{IP}_{3} \mathrm{R} 2$, and $\mathrm{IP}_{3} \mathrm{R} 3$ ); all of which are expressed in the endothelium [289-291]. $\mathrm{IP}_{3} \mathrm{R}$ is a tetrameric calcium channel with 6 transmembrane domains that facilitates storedcalcium release from the ER into the cytosol in response to $\mathrm{IP}_{3}$ synthesis. While $\mathrm{IP}_{3} \mathrm{R} 1$ has been demonstrated to localize to the ER within MEJ projections in vivo [132, $133,292]$, it exhibits diffuse staining throughout the ER of endothelial cells in culture [132]. However, $\mathrm{IP}_{3} \mathrm{R} 2$ and $\mathrm{IP}_{3} \mathrm{R} 3$ are localized in regions of the ER outside of the MEJ $[133,290]$. The importance of endothelial $\mathrm{IP}_{3} \mathrm{R}$ subtypes in systemic blood pressure regulation has been studied in vivo with conflicting results. Deletion of $\mathrm{IP}_{3} \mathrm{R} 1$ under the Tie2-Cre, which is expressed in all endothelial cells and hematopoietic cells throughout development, was initially described to reduce ACh-induced vasodilation and increase basal blood pressure [293]. Deletion of the same subtype under an inducible endothelial cell-specific Cre recombinase (PDGF receptor $\beta$ ) exhibited normal vascular reactivity and systemic blood pressure. However, when all 3 subtypes were genetically deleted in endothelial cells, the mice exhibited reduced plasma NO, vasodilation in response to $\mathrm{ACh}$, and eNOS phosphorylation, which all contributed to systemic hypertension [291]. Interestingly, attempts to reproduce the previously reported findings of $\mathrm{IP}_{3} \mathrm{R} 1$ deletion under the Tie2:Cre [293] were unsuccessful [291]. Taken together, this suggests functional redundancy between the isoforms of $\mathrm{IP}_{3} \mathrm{R}$ despite their localization differences.

$\mathrm{IP}_{3} \mathrm{R}$-mediated calcium events in the endothelium contribute to the generation of myogenic tone. Calcium influx can be triggered by low intraluminal pressure via TRPV4 in the MEJ. This promotes the activation of IP3R, which in turn activates $\mathrm{IK}_{\mathrm{Ca}}$ [294]. Thus, at low intraluminal pressure, hyperpolarization of the EC and SMC membrane reduces myogenic tone, likely acting to stabilize local blood flow in the tissue.

Endothelial barrier function is regulated in part by $\mathrm{IP}_{3} \mathrm{R}$ clustering within the ER membrane. Clustering amplifies $\mathrm{IP}_{3} \mathrm{R}$-mediated $\mathrm{Ca}^{2+}$ events, as $\mathrm{Ca}^{2+}$ released following activation of one channel promotes activation of other $\mathrm{IP}_{3} \mathrm{Rs}$ within close proximity [295]. In human lung microvascular endothelial cells, $\mathrm{IP}_{3} \mathrm{R}$ clustering via microtubule interactions is required for $\alpha$-thrombininduced adhesion disassembly [296].

\section{SK3, TRPV4, and Caveolae}

Caveolae microdomains on the plasma membrane are integral for vasodilation via EDH. EDH involves potassium efflux through calcium-sensitive small and intermediate conductance potassium channels $\left(\mathrm{SK}_{\mathrm{Ca}}\right.$ and $\mathrm{IK}_{\mathrm{Ca}}$, respectively). Recent work suggests that TRPV4 channels facilitate local calcium influx required to stimulate $\mathrm{SK}_{\mathrm{Ca}} /$ $\mathrm{IK}_{\mathrm{Ca}}$ activity [128, 278, 286, 287, 294, 297]. TRPV4 is largely localized to the cell periphery [297], though, as discussed in our abluminal section, its expression has also been noted in the MEJ $[128,294]$. SK3 exhibits a homogenous distribution on luminal and abluminal membranes 
[297]. However, both TRPV4 and SK3 are enriched on caveolae, which illustrates a role for caveolae in constructing the microdomain [278, 286, 287, 297]. Here, Cav1 acts as a scaffolding protein, generating $50-100 \mathrm{~nm}$ membrane invaginations that localize calcium signaling events. In fact, EDH is diminished in endothelium of global Cav1 knockouts but can be rescued by reexpression of Cav1 only in endothelial cells [298], indicating that TRPV4 is unable to activate SK3 activity without a means to restrict their localization on the membrane. Interestingly, the peripheral localization of TRPV4, which does not colocalize with SK3, appears to be dependent on SK3 expression, as TRPV4 distribution at the periphery is lost in mesenteric arteries collected from endothelialspecific SK3 ${ }^{-1-}$ mice [297]. The sum of the data suggests an important role for caveolae microdomains in the recruitment of TRPV4 and SK channels to facilitate efficient stimulation of SK activity and EDH.

\section{Go with the Flow: Shear Stress Regulates Planar Cell Polarity in Endothelial Cells}

Planar cell polarity describes the collective alignment of cell polarity along one axis of a tissue. Early works contended whether endothelial cells exhibited planar cell polarity $[30,250]$. The work was confounded by observed differences between arteriolar and venous vascular beds, concluding that endothelial cells polarize due to their position in relation to the heart. Today, we understand that shear stress, the frictional force generated by blood flow, orients endothelial planar cell polarity. Due to the morphology of vascular tissue, the planar cell polarity of the endothelium can also be referenced as axial polarity, in which the longitudinal axis of the vessel can be further segmented into upstream and downstream regions.

The vascular endothelium exhibits a high degree of phenotypic plasticity that is determined in part by shear stress acting as a biomechanical cue. The different types and rates of flow in various vascular beds determine how shear stress regulates endothelial morphology. Large conduit arteries must contend with the volume of blood rapidly ejected from each ventricular contraction of the heart. Thus, the endothelium of conduit arteries is exposed to pulsatile flow patterns at a relatively high speed $\left(\sim 10 \mathrm{dyn} / \mathrm{cm}^{2}\right)$. The elasticity of the vessel wall of conduit arteries helps to convert pulsatile flow in large arteries to continuous laminar flow in smaller resistance arteries. Arterioles and capillaries experience the highest degree of shear stress, at $\sim 50$ and $40 \mathrm{dyn} / \mathrm{cm}^{2}$, respectively. This decreases dramatically at the venules $\left(\sim 15 \mathrm{dyn} / \mathrm{cm}^{2}\right)$, with the lowest values of shear stress occurring in the vena cava $\left(\sim 1 \mathrm{dyn} / \mathrm{cm}^{2}\right)[299,300]$.

This differential shear stress alters the morphology of endothelial cells and can orchestrate planar polarity. Arterial endothelial cells are narrow and elongated in the direction of flow, whereas venous endothelial cells are generally shorter and wider (e.g., with claudin- 5 shown in Fig. 4). In arteries, the endothelial microtubule organizing center (MTOC) is localized downstream of the nucleus $[30,31]$. Large veins exhibit MTOC localization upstream of the nucleus [30,31]. Similar polarization patterns have been reported in localization of the perinuclear Golgi apparatus, which is localized upstream of the nucleus in bovine endothelial cells grown under laminar shear stress in culture [301]. Polarization of the Golgi upstream of nuclei has also been observed in live zebrafish embryos using a fluorescent reporter for endothelial cells, Tg(fli1a:B4GALT1-mCherry). The Golgi was localized upstream of endothelial nuclei in the dorsal aorta and branching arteries [302]. In contrast, in the posterior cardinal vein, where shear stress is much lower, endothelial cells do not exhibit Golgi polarization [302].

Upon the initiation of shear stress conditions in vitro, the endothelium undergoes rapid morphological changes as the cells elongate and orient in the direction of flow. Cytoskeletal alterations include MTOC reorganization as well as the formation of actin stress fibers that also align with flow [31, 303-305]. In addition, cell-cell junctional complexes undergo partial disassembly and reorganization. VE-cadherin, $\alpha$-catenin, and $\beta$-catenin form adherens plaques at the end of actin stress fibers that become stabilized by plakoglobin recruitment over the next $48 \mathrm{~h}$ [305]. The reorganization of the cytoskeleton and adherens junctions likely stabilize cell-cell contact and endothelial barrier integrity. Integrins on the abluminal membrane also become activated following exposure to shear stress [306, 307], which is thought to promote MTOC reorganization.

\section{Mechanosensors of Blood Flow}

Shear forces must be transduced into downstream signaling cascades via endothelial mechanosensors. Understanding and identifying such mechanosensors can help us better understand how planar polarity is regulated. These mechanosensors of shear stress would need to be localized on the luminal membrane such that they receive direct input from the vessel's lumen. While the identity of the predominate endothelial mechanosensor is not precisely understood, many proteins and organelles have been pro-
80

J Vasc Res 2021;58:65-91

DOI: $10.1159 / 000512618$
Wolpe/Ruddiman/Hall/Isakson 
posed for the role, including mechanically gated channels $[308,309]$, mechanosensitive receptors [272, 310], GPCRs [311-313], mechanosensitive enzymes [314], primary cilia [315,316], the glycocalyx [317], and the nucleus itself [318]. It is possible that a master regulator of endothelial mechanosensation does not exist and each of the proposed sensors act in concert to confer the morphological and regulatory changes occurring downstream of flow. Thorough reviews of proposed mechanosensors are available for further reading [319, 320]; however, this review will highlight mechanosensation via the cation channel Piezol; the complex composed of PECAM1, VEGFR2/3, and VE-cadherin; and the contributions of the transcription factor yes-associated protein (YAP).

Piezo proteins are mechanically activated cation channels. Expression of Piezo1 is sufficient to enable HEK293T cells, which are normally unresponsive to shear stress, to exhibit shear stress-induced calcium influx [308]. Piezo1 is expressed in endothelial cells as early as embryonic age 9.5 (E9.5) [321]. Endothelial Piezo1 expression is vital, as deficiency of Piezo1 is embryonically lethal in both global [308, 321] and endothelial cell-specific [308] knockouts due to growth retardation and defects in vascular development. This illustrates the essential role of endothelial mechanosensing during vascular development and further demonstrates the importance of Piezol activity at this early stage of development. Furthermore, loss of Piezol expression was found to reduce shear-evoked calcium influx in endothelial cells isolated from knockout mice [308] as well as cultured cells undergoing RNAi [322]. Piezo1 expression is also required for the morphological changes that endothelial cells undergo in response to shear stress [308, 321]. At the tissue level, this causes endothelial cells in haploinsufficient arteries to fail to align in the direction of flow [308]. While canonically studied for its role in development, the use of an inducible endothelial cell-specific Piezol knockout mouse enabled investigations into the role of Piezol in adult endothelial tissue. Flow-induced vasodilation was impaired in mesenteric resistance arteries from mice deficient in endothelial Piezo1, indicating a mechanosensory role in vessel function [322]. While the signaling mechanism downstream of shear-induced Piezol activation has yet to be elucidated, the GPCR $\mathrm{Ga}_{\mathrm{q} / 11}$, the purinergic receptor $\mathrm{P}_{2} \mathrm{Y}_{2}$, and the ATP-release channel Panx1 have all been implicated in regulating flow-mediated dilation [322]. Last, the localization of Piezo1 on endothelial cells, while assumed to be present on the luminal surface, still needs to be explicitly studied via immunohistochemistry or electron microscopy experiments.

Protein Localization in Endothelium
Endothelial mechanosensors are present within interendothelial junctions. PECAM-1, VEGFR2/3, and VEcadherin form a mechanosensory complex at interendothelial junctions, which is necessary and sufficient for shear-induced integrin activation [272]. PECAM-1 has also been shown to directly transmit mechanical force. Mechanical force transduction experiments using magnetic beads coated with antibody against PECAM-1 were used to demonstrate that PECAM-1 sustains piconewtons of force under shear stress [323] and to show that direct force applied to PECAM-1 is sufficient to activate many shear-induced signaling pathways [272, 324]. In fact, tyrosine phosphorylation of PECAM-1 by Fyn tyrosine kinase is the first cellular response to the onset of shear stress on endothelial cells [325]. Despite its essential role in endothelial mechanosensing, PECAM-1-null mice are healthy and fertile [326], though not without an impaired shear-induced vasodilatory response [327]. The mild phenotype associated with the PECAM-1 knockout suggests that redundant mechanisms may exist. While previously thought to act simply as an adaptor protein in the complex, VE-cadherin has recently been shown to have mechanosensitive properties [328]. However, it is not yet understood whether mechanosensing through VE-cadherin occurs in vivo. Interestingly, VE-cadherin expression is required for mechanosensation by $\mathrm{PE}$ CAM-1 [272]. Furthermore, the transmembrane domain of VE-cadherin facilitates ligand-independent activation of VEGFR2/3 [310]. Activation of VEGFR2/3 initiates the activation of multiple shear-activated signaling pathways including AKT kinase [272, 310], PI3K [272], eNOS [272], and integrins $[272,306]$, though there is no evidence that VEGFR2 acts as a primary mechanosensor [329].

The transcriptional coactivator YAP has also been implicated in endothelial mechanosensation. Its canonical role in the Hippo pathway has been well described. Briefly, the activated YAP translocates from the cytoplasm into the nucleus, where it can interact with TEA domains family of proteins to regulate transcription until it becomes phosphorylated and exported from the nucleus. However, recent work supports a mechanosensing role for YAP in the endothelium. First, YAP-deficient mice exhibit vascular defects in the yolk sac, similar to those observed in the Piezo1-knockout mice [330]. In addition, mechanical perturbations can control the nuclear shuttling of YAP through interactions with F-actin [331], suggesting that the mechanosensory role that YAP confers is to alter transcription in response to shear stress. Transgenic zebrafish have been used to observe dynamic 
YAP localization in endothelium, which demonstrated that in vivo shear stress promotes nuclear localization of YAP [332]. Further research is required to determine how mechanical stimuli facilitate the activation of endothelial YAP. The YAP-mediated transcriptomic alterations may promote the maintenance of polarized morphology.

Planar cell polarity adds another dimension to the intricate spatial distribution of the endothelium. The circulation provides a dynamic directional stimulus, which is sensed by mechanosensors and transduced to second messengers, phosphorylation cascades, and gene expression differences. Altogether, planar cell polarity facilitates precise spatial regulation in the endothelium. Much of the literature on endothelial mechanosensation and planar cell polarity has focused on large arteries due to the impact of laminar versus disturbed flow in the progression of atherosclerosis. As such, there is an unfortunate dearth of evidence for mechanosensation in the endothelium of small resistance arteries. However, GPR68, a class A rhodopsin-like GPCR, was recently identified in an siRNA screen as a direct mechanosensor and was shown to be expressed exclusively in the endothelium of small diameter arteries in the mesentery, pancreas, liver, and bladder. Furthermore, flow-mediated dilation was diminished in the GPR68-knockout mice and murine primary microvascular endothelial cells were unable to generate calcium transients in response to laminar flow following treatment with siRNA [333]. This work may stimulate further investigation into mechanosensation and planar cell polarity in the endothelium of small arteries.

\section{Conclusion}

Despite their squamous nature, endothelial cells still demonstrate protein localization and polarity that is crucial for their various physiological functions. As reviewed here, endothelial cells express anticoagulants, receptors, and enzymes among the glycocalyx on their luminal surface to respond to circulating factors. In general, these luminally polarized proteins are found in both arteries and veins, and expression differences are not well studied. In contrast, the abluminal protein localization in resistance arterioles is absent in the venous endothelium. Along this surface are MEJs, which are endothelial extensions that make heterocellular contact with smooth muscle cells and exhibit specific protein localization. Ultimately, the proteins at the MEJ func- tion to regulate the vasodilatory signals and tightly control total peripheral resistance. Within the MEJ are even smaller microdomain pockets, termed caveolae, which also house factors crucial to vasodilatory pathways. Although caveolae are not unique to endothelial cells, they are enriched within the MEJ in the arteriolar endothelium. Luminal and abluminal polarization go beyond surface expression and is also characteristic of endothelial secretions. Endothelial planar polarity includes interendothelial junctions, where tight and adherens junctions create a selective barrier to the underlying layers of the arterial wall. Gap junctions present at endothelial cell-endothelial cell borders allow the endothelium to function as a coordinated monolayer. Mechanosensory complexes are also polarized along this axis. Their distribution is patterned along the direction of blood flow to communicate cellular signals downstream of shear stress. Overall, endothelial polarity in both the luminalabluminal and planar axes is critical for arteriolar endothelial cells that are constantly responding to their extracellular environment. Future studies should examine the trafficking of luminal and abluminal proteins in the endothelium, which are likely differentially regulated and may offer novel therapeutic targets for hypertension, diabetes, and hyperlipidemia.

\section{Conflict of Interest Statement}

The authors have no conflicts of interest to declare.

\section{Funding Sources}

This work was funded by NHLBI 1F31HL149221-01 (A.G.W.), NHLBI 1F31HL149228-01 (C.A.R.), and NIH HL088554 (B.E.I.).

\section{Author Contributions}

A.G.W. and C.A.R. contributed equally to the writing of the manuscript. A.G.W. created Figures 1-3. C.A.R. created Figure 4. P.J.H. reviewed the manuscript and made important intellectual contributions. P.J.H. conceptualized and created Table 1. B.E.I. conceptualized the original idea and critically reviewed the manuscript throughout the writing process. 


\section{References}

1 Florey. The endothelial cell. Br Med J. 1966; 2(5512):487-90.

2 Wolff JR, Chao TI. Cytoarchitectonics of nonneuronal cells in the central nervous system. Adv Mol Cell Biol. 2003;31:1-51.

3 Haraldsen G, Kvale D, Lien B, Farstad IN, Brandtzaeg P. Cytokine-regulated expression of E-selectin, intercellular adhesion molecule-1 (ICAM-1), and vascular cell adhesion molecule-1 (VCAM-1) in human microvascular endothelial cells. J Immunol. 1996; 156(7):2558-65.

4 Wong D, Dorovini-Zis K. Regulation by cytokines and lipopolysaccharide of E-selectin expression by human brain microvessel endothelial cells in primary culture. J Neuropathol Exp Neurol. 1996;55(2):225-35.

5 Cornford EM, Hyman S. Localization of brain endothelial luminal and abluminal transporters with immunogold electron microscopy. NeuroRx. 2005;2(1):27-43.

6 van Haaren PM, VanBavel E, Vink H, Spaan JA. Localization of the permeability barrier to solutes in isolated arteries by confocal microscopy. Am J Physiol Heart Circ Physiol. 2003; 285(6):H2848-56.

7 van den Berg BM, Vink H, Spaan JA. The endothelial glycocalyx protects against myocardial edema. Circ Res. 2003;92(6):592-4.

8 Ihrcke NS, Wrenshall LE, Lindman BJ, Platt JL. Role of heparan sulfate in immune systemblood vessel interactions. Immunol Today. 1993;14(10):500-5.

9 Sarrazin S, Lamanna WC, Esko JD. Heparan sulfate proteoglycans. Cold Spring Harb Perspect Biol. 2011;3(7):a004952.

10 Edward Conrad H. Heparin-binding proteins. San Diego, CA: Academic Press; 1998.

11 Shimada K, Kobayashi M, Kimura S, Nishinaga $\mathrm{M}$, Takeuchi $\mathrm{K}$, Ozawa T. Anticoagulant heparin-like glycosaminoglycans on endothelial cell surface. Jpn Circ J. 1991;55(10): 1016-21.

12 Parker KA, Tollefsen DM. The protease specificity of heparin cofactor II. Inhibition of thrombin generated during coagulation. J Biol Chem. 1985;260(6):3501-5.

13 Kato H. Regulation of functions of vascular wall cells by tissue factor pathway inhibitor: basic and clinical aspects. Arterioscler Thromb Vasc Biol. 2002;22(4):539-48.

14 Atha DH, Lormeau JC, Petitou M, Rosenberg $\mathrm{RD}$, Choay J. Contribution of monosaccharide residues in heparin binding to antithrombin III. Biochemistry. 1985;24(23): 6723-9.

15 Lindahl U, Bäckström G, Thunberg L, Leder IG. Evidence for a 3-O-sulfated D-glucosamine residue in the antithrombin-binding sequence of heparin. Proc Natl Acad Sci U S A. $1980 ; 77(11): 6551-5$
16 Mosier PD, Krishnasamy C, Kellogg GE, Desai UR. On the specificity of heparin/heparan sulfate binding to proteins. Anion-binding sites on antithrombin and thrombin are fundamentally different. PLoS One. 2012;7(11): e48632.

17 Plotnikov AN, Schlessinger J, Hubbard SR, Mohammadi M. Structural basis for FGF receptor dimerization and activation. Cell. 1999;98(5):641-50.

18 Rider CC. Heparin/heparan sulphate binding in the TGF-beta cytokine superfamily. Biochem Soc Trans. 2006;34(Pt 3):458-60.

19 Feyzi E, Lustig F, Fager G, Spillmann D, Lindahl U, Salmivirta M. Characterization of heparin and heparan sulfate domains binding to the long splice variant of platelet-derived growth factor A chain. J Biol Chem. 1997; 272(9):5518-24.

20 Lyon M, Deakin JA, Mizuno K, Nakamura T, Gallagher JT. Interaction of hepatocyte growth factor with heparan sulfate. Elucidation of the major heparan sulfate structural determinants. J Biol Chem. 1994;269(15): 11216-23.

21 Robinson CJ, Mulloy B, Gallagher JT, Stringer SE. VEGF165-binding sites within heparan sulfate encompass two highly sulfated domains and can be liberated by K5 lyase. J Biol Chem. 2006;281(3):1731-40.

22 Burgess WH, Maciag T. The heparin-binding (fibroblast) growth factor family of proteins. Annu Rev Biochem. 1989;58:575-606.

23 Ornitz DM, Yayon A, Flanagan JG, Svahn CM, Levi E, Leder P. Heparin is required for cell-free binding of basic fibroblast growth factor to a soluble receptor and for mitogenesis in whole cells. Mol Cell Biol. 1992;12(1): 240-7.

24 Spivak-Kroizman T, Lemmon MA, Dikic I, Ladbury JE, Pinchasi D, Huang J, et al. Heparin-induced oligomerization of FGF molecules is responsible for FGF receptor dimerization, activation, and cell proliferation. Cell. 1994;79(6):1015-24.

25 Reitsma S, Slaaf DW, Vink H, van Zandvoort MA, oude Egbrink MG. The endothelial glycocalyx: composition, functions, and visualization. Pflugers Arch. 2007;454(3):345-59.

26 Florian JA, Kosky JR, Ainslie K, Pang Z, Dull RO, Tarbell JM. Heparan sulfate proteoglycan is a mechanosensor on endothelial cells. Circ Res. 2003;93(10):e136-42.

27 Pahakis MY, Kosky JR, Dull RO, Tarbell JM. The role of endothelial glycocalyx components in mechanotransduction of fluid shear stress. Biochem Biophys Res Commun. 2007; 355(1):228-33.

28 Cooper S, Emmott A, McDonald KK, Campeau MA, Leask RL. Increased MMP activity in curved geometries disrupts the endothelial cell glycocalyx creating a proinflammatory environment. PLoS One. 2018;13(8): e0202526.
29 Hecker M, Mülsch A, Bassenge E, Busse R. Vasoconstriction and increased flow: two principal mechanisms of shear stress-dependent endothelial autacoid release. Am J Physiol. 1993;265(3 Pt 2):H828-33.

30 Rogers KA, McKee NH, Kalnins VI. Preferential orientation of centrioles toward the heart in endothelial cells of major blood vessels is reestablished after reversal of a segment. Proc Natl Acad Sci U S A. 1985;82(10):3272-6.

31 McCue S, Dajnowiec D, Xu F, Zhang M, Jackson MR, Langille BL. Shear stress regulates forward and reverse planar cell polarity of vascular endothelium in vivo and in vitro. Circ Res. 2006;98(7):939-46.

32 Papaioannou TG, Stefanadis C. Vascular wall shear stress: basic principles and methods. Hellenic J Cardiol. 2005;46(1):9-15.

33 Kamiya A, Bukhari R, Togawa T. Adaptive regulation of wall shear stress optimizing vascular tree function. Bull Math Biol. 1984; 46(1):127-37.

34 Chappell D, Hofmann-Kiefer K, Jacob M, Rehm M, Briegel J, Welsch U, et al. TNF-alpha induced shedding of the endothelial glycocalyx is prevented by hydrocortisone and antithrombin. Basic Res Cardiol. 2009;104(1): 78-89.

35 Henry CB, Duling BR. TNF-alpha increases entry of macromolecules into luminal endothelial cell glycocalyx. Am J Physiol Heart Circ Physiol. 2000;279(6):H2815-23.

36 Lukasz A, Hillgruber C, Oberleithner H, Kusche-Vihrog K, Pavenstädt H, Rovas A, et al. Endothelial glycocalyx breakdown is mediated by angiopoietin-2. Cardiovasc Res. 2017; 113(6):671-80.

37 Constantinescu AA, Vink H, Spaan JA. Endothelial cell glycocalyx modulates immobilization of leukocytes at the endothelial surface. Arterioscler Thromb Vasc Biol. 2003;23(9): 1541-7.

38 Tsukahara T, Kassell NF, Hongo K, Vollmer DG, Ogawa H. Muscarinic cholinergic receptors on the endothelium of human cerebral arteries. J Cereb Blood Flow Metab. 1989;9(6): 748-53.

39 Rivers RJ, Duling BR. Arteriolar endothelial cell barrier separates two populations of muscarinic receptors. Am J Physiol. 1992;262(4 Pt 2):H1311-5.

40 Bruning TA, Hendriks MG, Chang PC, Kuypers EA, van Zwieten PA. In vivo characterization of vasodilating muscarinic-receptor subtypes in humans. Circ Res. 1994;74(5): 912-9.

41 Milner P, Ralevic V, Hopwood AM, Fehér E, Lincoln J, Kirkpatrick KA, et al. Ultrastructural localisation of substance $\mathrm{P}$ and choline acetyltransferase in endothelial cells of rat coronary artery and release of substance P and acetylcholine during hypoxia. Experientia. 1989;45(2):121-5. 
42 Kirkpatrick CJ, Bittinger F, Nozadze K, Wessler I. Expression and function of the non-neuronal cholinergic system in endothelial cells. Life Sci. 2003;72(18-19):2111-6.

43 Zou Q, Leung SW, Vanhoutte PM. Transient receptor potential channel opening releases endogenous acetylcholine, which contributes to endothelium-dependent relaxation induced by mild hypothermia in spontaneously hypertensive rat but not Wistar-Kyoto rat arteries. J Pharmacol Exp Ther. 2015;354(2): $121-30$.

44 Wilson C, Lee MD, McCarron JG. Acetylcholine released by endothelial cells facilitates flow-mediated dilatation. J Physiol. 2016; 594(24):7267-307.

45 Parnavelas JG, Kelly W, Burnstock G. Ultrastructural localization of choline acetyltransferase in vascular endothelial cells in rat brain. Nature. 1985;316(6030):724-5.

46 Shu X, Ruddiman CA, Keller TCS, Keller AS, Yang Y, Good ME, et al. Heterocellular contact can dictate arterial function. Circ Res. 2019;124(10):1473-81.

47 Kemp BK, Cocks TM. Evidence that mechanisms dependent and independent of nitric oxide mediate endothelium-dependent relaxation to bradykinin in human small resistance-like coronary arteries. Br J Pharmacol. 1997;120(5):757-62.

48 Edwards G, Dora KA, Gardener MJ, Garland $\mathrm{CJ}$, Weston $\mathrm{AH} . \mathrm{K}+$ is an endothelium-derived hyperpolarizing factor in rat arteries. Nature. 1998;396(6708):269-72.

49 Garland CJ, Dora KA. EDH: endotheliumdependent hyperpolarization and microvascular signalling. Acta Physiol. 2017;219(1): $152-61$.

50 Figueroa CD, Marchant A, Novoa U, Förstermann U, Jarnagin K, Schölkens B, et al. Differential distribution of bradykinin $\mathrm{B}(2)$ receptors in the rat and human cardiovascular system. Hypertension. 2001;37(1):110-20.

51 Baydoun AR, Woodward B. Effects of bradykinin in the rat isolated perfused heart: role of kinin receptors and endothelium-derived relaxing factor. Br J Pharmacol. 1991;103(3): 1829-33.

52 Ohlmann P, Martínez MC, Schneider F, Stoclet JC, Andriantsitohaina R. Characterization of endothelium-derived relaxing factors released by bradykinin in human resistance arteries. Br J Pharmacol. 1997;121(4):657-64.

53 Schini VB, Boulanger C, Regoli D, Vanhoutte $\mathrm{PM}$. Bradykinin stimulates the production of cyclic GMP via activation of B2 kinin receptors in cultured porcine aortic endothelial cells. J Pharmacol Exp Ther. 1990;252(2): 581-5.

54 Pascoal IF, Umans JG. Effect of pregnancy on mechanisms of relaxation in human omental microvessels. Hypertension. 1996;28(2):183-7.

55 Jimenez AH, Tanner MA, Caldwell WM, Myers PR. Effects of oxygen tension on flow-induced vasodilation in porcine coronary resistance arterioles. Microvasc Res. 1996;51(3): $365-77$.
56 Biwer LA, Taddeo EP, Kenwood BM, Hoehn KL, Straub AC, Isakson BE. Two functionally distinct pools of eNOS in endothelium are facilitated by myoendothelial junction lipid composition. Biochim Biophys Acta. 2016; 1861(7):671-9.

57 Prat A, Biernacki K, Pouly S, Nalbantoglu J, Couture R, Antel JP. Kinin B1 receptor expression and function on human brain endothelial cells. J Neuropathol Exp Neurol. 2000; 59(10):896-906.

58 Ventura PDS, Carvalho CPF, Barros NMT, Martins-Silva L, Dantas EO, Martinez C, et al. Malaria infection promotes a selective expression of kinin receptors in murine liver. Malar J. 2019;18(1):213

59 Leeb-Lundberg LM, Marceau F, Müller-Esterl W, Pettibone DJ, Zuraw BL. International union of pharmacology. XLV. Classification of the kinin receptor family: from molecular mechanisms to pathophysiological consequences. Pharmacol Rev. 2005;57(1):27-77.

$60 \mathrm{Ng} \mathrm{KK}$, Vane JR. Fate of angiotensin I in the circulation. Nature. 1968;218(5137):144-50.

61 Caldwell PR, Seegal BC, Hsu KC, Das M, Soffer RL. Angiotensin-converting enzyme: vascular endothelial localization. Science. 1976; 191(4231):1050-1.

62 Ryan US, Ryan JW, Whitaker C, Chiu A. Localization of angiotensin converting enzyme (kininase II). II. Immunocytochemistry and immunofluorescence. Tissue Cell. 1976;8(1): 125-45.

63 Fukuhara M, Geary RL, Diz DI, Gallagher PE, Wilson JA, Glazier SS, et al. Angiotensin-converting enzyme expression in human carotid artery atherosclerosis. Hypertension. 2000; 35(1 Pt 2):353-9.

64 Metzger R, Franke FE, Bohle RM, Alhenc-Gelas F, Danilov SM. Heterogeneous distribution of angiotensin I-converting enzyme (CD143) in the human and rat vascular systems: vessel, organ and species specificity. Microvasc Res. 2011;81(2):206-15.

65 Nora EH, Munzenmaier DH, Hansen-Smith FM, Lombard JH, Greene AS. Localization of the ANG II type 2 receptor in the microcirculation of skeletal muscle. Am J Physiol. 1998; 275(4 Pt 2):H1395-403.

66 Philogene MC, Bagnasco S, Kraus ES, Montgomery RA, Dragun D, Leffell MS, et al. Antiangiotensin II type 1 receptor and anti-endothelial cell antibodies: a cross-sectional analysis of pathological findings in allograft biopsies. Transplantation. 2017;101(3):60815.

67 Pueyo ME, Michel JB. Angiotensin II receptors in endothelial cells. Gen Pharmacol. 1997;29(5):691-6.

68 Gunther S, Gimbrone MA Jr, Alexander RW. Regulation by angiotensin II of its receptors in resistance blood vessels. Nature. 1980; 287(5779):230-2.

69 Pries AR, Kuebler WM. Normal endothelium. Handb Exp Pharmacol. 2006(176 Pt 1): $1-40$
70 Ramkhelawon B, Vilar J, Rivas D, Mees B, de Crom R, Tedgui A, et al. Shear stress regulates angiotensin type 1 receptor expression in endothelial cells. Circ Res. 2009;105(9):869-75.

$71 \mathrm{Wu} \mathrm{JN}$, Edwards D, Berecek KH. Changes in renal angiotensin II receptors in spontaneously hypertensive rats by early treatment with the angiotensin-converting enzyme inhibitor captopril. Hypertension. 1994;23(6 Pt 2):819-22.

72 Wiemer G, Scholkens BA, Wagner A, Heitsch $\mathrm{H}$, Linz W. The possible role of angiotensin II subtype AT2 receptors in endothelial cells and isolated ischemic rat hearts. J Hypertens Suppl. 1993;11(5):S234-5.

73 Nio Y, Matsubara H, Murasawa S, Kanasaki M, Inada M. Regulation of gene transcription of angiotensin II receptor subtypes in myocardial infarction. J Clin Invest. 1995;95(1): 46-54.

74 Pueyo ME, Arnal JF, Rami J, Michel JB. Angiotensin II stimulates the production of $\mathrm{NO}$ and peroxynitrite in endothelial cells. Am J Physiol. 1998;274(1 Pt 1):C214-20.

75 Bayraktutan U, Ulker S. Effects of angiotensin II on nitric oxide generation in proliferating and quiescent rat coronary microvascular endothelial cells. Hypertens Res. 2003;26(9): 749-57.

76 Boulanger CM, Caputo L, Lévy BI. Endothelial AT1-mediated release of nitric oxide decreases angiotensin II contractions in rat carotid artery. Hypertension. 1995;26(5):752-7.

77 Stoll M, Steckelings UM, Paul M, Bottari SP, Metzger R, Unger T. The angiotensin AT2receptor mediates inhibition of cell proliferation in coronary endothelial cells. J Clin Invest. 1995;95(2):651-7.

78 Dimmeler S, Rippmann V, Weiland U, Haendeler J, Zeiher AM. Angiotensin II induces apoptosis of human endothelial cells. Protective effect of nitric oxide. Circ Res. 1997;81(6):970-6.

79 Yadav VR, Nayeem MA, Tilley SL, Mustafa SJ. Angiotensin II stimulation alters vasomotor response to adenosine in mouse mesenteric artery: role for $\mathrm{A} 1$ and $\mathrm{A} 2 \mathrm{~B}$ adenosine receptors. Br J Pharmacol. 2015;172(20):4959-69.

80 Gunther S, Gimbrone MA Jr, Alexander RW. Identification and characterization of the high affinity vascular angiotensin II receptor in rat mesenteric artery. Circ Res. 1980;47(2):278-86.

81 Emori T, Hirata Y, Ohta K, Kanno K, Eguchi $S$, Imai T, et al. Cellular mechanism of endothelin-1 release by angiotensin and vasopressin. Hypertension. 1991;18(2):165-70.

82 Ferri C, Desideri G, Baldoncini R, Bellini C, Valenti M, Santucci A, et al. Angiotensin II increases the release of endothelin-1 from human cultured endothelial cells but does not regulate its circulating levels. Clin Sci. 1999; 96(3):261-70.

83 Gillespie MN, Owasoyo JO, McMurtry IF, O'Brien RF. Sustained coronary vasoconstriction provoked by a peptidergic substance released from endothelial cells in culture. Pharmacol Exp Ther. 1986;236(2):339-43. 
84 Hickey KA, Rubanyi G, Paul RJ, Highsmith RF. Characterization of a coronary vasoconstrictor produced by cultured endothelial cells. Am J Physiol. 1985;248(5 Pt 1):C550-6.

85 Loesch A. Localisation of endothelin- 1 and its receptors in vascular tissue as seen at the electron microscopic level. Curr Vasc Pharmacol. 2005;3(4):381-92.

86 Seo B, Oemar BS, Siebenmann R, von Segesser L, Lüscher TF. Both ETA and ETB receptors mediate contraction to endothelin-1 in human blood vessels. Circulation. 1994;89(3): 1203-8.

87 Hirata Y, Emori T, Eguchi S, Kanno K, Imai T, Ohta K, et al. Endothelin receptor subtype $B$ mediates synthesis of nitric oxide by cultured bovine endothelial cells. J Clin Invest. 1993;91(4):1367-73.

88 Warner TD, Mitchell JA, de Nucci G, Vane JR. Endothelin-1 and endothelin-3 release EDRF from isolated perfused arterial vessels of the rat and rabbit. J Cardiovasc Pharmacol. 1989;13(Suppl 5):S85-8; .

89 Wendel M, Knels L, Kummer W, Koch T. Distribution of endothelin receptor subtypes ETA and ETB in the rat kidney. J Histochem Cytochem. 2006;54(11):1193-203.

90 Yokomori H, Oda M, Yasogawa Y, Nishi Y, Ogi M, Takahashi M, et al. Enhanced expression of endothelin $\mathrm{B}$ receptor at protein and gene levels in human cirrhotic liver. Am J Pathol. 2001;159(4):1353-62.

91 Yokomori H, Oda M, Ogi M, Kamegaya Y, Tsukada N, Nakamura M, et al. Enhanced expression of endothelin receptor subtypes in cirrhotic rat liver. Liver. 2001;21(2):114-22.

92 Davie N, Haleen SJ, Upton PD, Polak JM, Yacoub $\mathrm{MH}$, Morrell NW, et al. ET(A) and ET(B) receptors modulate the proliferation of human pulmonary artery smooth muscle cells. Am J Respir Crit Care Med. 2002;165(3): 398-405.

93 Soma S, Takahashi H, Muramatsu M, Oka M, Fukuchi Y. Localization and distribution of endothelin receptor subtypes in pulmonary vasculature of normal and hypoxia-exposed rats. Am J Respir Cell Mol Biol. 1999;20(4): 620-30.

94 Filep JG, Battistini B, Côté YP, Beaudoin AR, Sirois P. Endothelin-1 induces prostacyclin release from bovine aortic endothelial cells. Biochem Biophys Res Commun. 1991;177(1): 171-6.

95 Russell FD, Skepper JN, Davenport AP. Detection of endothelin receptors in human coronary artery vascular smooth muscle cells but not endothelial cells by using electron microscope autoradiography. J Cardiovasc Pharmacol. 1997;29(6):820-6.

96 Iranami H, Hatano Y, Tsukiyama Y, Maeda H, Mizumoto K. A beta-adrenoceptor agonist evokes a nitric oxide-cGMP relaxation mechanism modulated by adenylyl cyclase in rat aorta. Halothane does not inhibit this mechanism. Anesthesiology. 1996;85(5):1129-38.
97 Briones AM, Daly CJ, Jimenez-Altayo F, Martinez-Revelles S, Gonzalez JM, McGrath JC, et al. Direct demonstration of beta1- and evidence against beta2- and beta3-adrenoceptors, in smooth muscle cells of rat small mesenteric arteries. Br J Pharmacol. 2005; 146(5):679-91.

98 Molenaar P, Malta E, Jones CR, Buxton BF, Summers RJ. Autoradiographic localization and function of beta-adrenoceptors on the human internal mammary artery and saphenous vein. Br J Pharmacol. 1988;95(1):22533.

99 Yang J, Sun H, Zhang J, Hu M, Wang J, Wu $\mathrm{G}$, et al. Regulation of $\beta$-adrenergic receptor trafficking and lung microvascular endothelial cell permeability by Rab5 GTPase. Int J Biol Sci. 2015;11(8):868-78.

100 Burnstock G. Dual control of vascular tone and remodelling by ATP released from nerves and endothelial cells. Pharmacol Rep. 2008;60(1):12-20.

101 Haas JA, Osswald H. Adenosine induced fall in glomerular capillary pressure. Effect of ureteral obstruction and aortic constriction in the Munich-Wistar rat kidney. Naunyn Schmiedebergs Arch Pharmacol. 1981; 317(1):86-9.

102 Lohman AW, Billaud M, Isakson BE. Mechanisms of ATP release and signalling in the blood vessel wall. Cardiovasc Res. 2012; 95(3):269-80

103 Simonsen U, García-Sacristán A, Prieto D. Involvement of ATP in the non-adrenergic non-cholinergic inhibitory neurotransmission of lamb isolated coronary small arteries. Br J Pharmacol. 1997;120(3):411-20.

104 Good ME, Eucker SA, Li J, Bacon HM, Lang SM, Butcher JT, et al. Endothelial cell Pannexin 1 modulates severity of ischemic stroke by regulating cerebral inflammation and myogenic tone. JCI Insight. 2018;3(6): e96272.

105 Moser TL, Kenan DJ, Ashley TA, Roy JA, Goodman MD, Misra UK, et al. Endothelial cell surface F1-F0 ATP synthase is active in ATP synthesis and is inhibited by angiostatin. Proc Natl Acad Sci U S A. 2001; 98(12):6656-61

106 Bodin P, Burnstock G. ATP-stimulated release of ATP by human endothelial cells. J Cardiovasc Pharmacol. 1996;27(6):872-5.

107 Bodin P, Bailey D, Burnstock G. Increased flow-induced ATP release from isolated vascular endothelial cells but not smooth muscle cells. Br J Pharmacol. 1991;103(1): $1203-5$.

108 Bodin P, Burnstock G. Synergistic effect of acute hypoxia on flow-induced release of ATP from cultured endothelial cells. Experientia. 1995;51(3):256-9.

109 Faigle M, Seessle J, Zug S, El Kasmi KC, Eltzschig HK. ATP release from vascular endothelia occurs across Cx43 hemichannels and is attenuated during hypoxia. PLoS One. 2008;3(7):e2801.
110 Lee MD, Wilson C, Saunter CD, Kennedy C, Girkin JM, McCarron JG. Spatially structured cell populations process multiple sensory signals in parallel in intact vascular endothelium. Sci Signal. 2018;11(561): eaar4411.

111 Moccia F, Baruffi S, Spaggiari S, Coltrini D, Berra-Romani R, Signorelli S, et al. P2y1 and $\mathrm{P} 2 \mathrm{y} 2$ receptor-operated $\mathrm{Ca} 2+$ signals in primary cultures of cardiac microvascular endothelial cells. Microvasc Res. 2001;61(3): 240-52.

112 Raqeeb A, Sheng J, Ao N, Braun AP. Purinergic $\mathrm{P} 2 \mathrm{Y} 2$ receptors mediate rapid $\mathrm{Ca} 2+$ mobilization, membrane hyperpolarization and nitric oxide production in human vascular endothelial cells. Cell Calcium. 2011; 49(4):240-8.

113 Schwiebert LM, Rice WC, Kudlow BA, Taylor AL, Schwiebert EM. Extracellular ATP signaling and P2X nucleotide receptors in monolayers of primary human vascular endothelial cells. Am J Physiol Cell Physiol. 2002;282(2):C289-301.

114 Uehara K, Uehara A. P2Y1, P2Y6, and $\mathrm{P} 2 \mathrm{Y} 12$ receptors in rat splenic sinus endothelial cells: an immunohistochemical and ultrastructural study. Histochem Cell Biol. 2011;136(5):557-67.

115 Ray FR, Huang W, Slater M, Barden JA. Purinergic receptor distribution in endothelial cells in blood vessels: a basis for selection of coronary artery grafts. Atherosclerosis. 2002;162(1):55-61.

116 Yamamoto K, Sokabe T, Matsumoto T, Yoshimura K, Shibata M, Ohura N, et al. Impaired flow-dependent control of vascular tone and remodeling in P2X4-deficient mice. Nat Med. 2006;12(1):133-7.

117 dela Paz NG, D’Amore PA. Arterial versus venous endothelial cells. Cell Tissue Res. 2009;335(1):5-16.

118 Maruyama I, Bell CE, Majerus PW. Thrombomodulin is found on endothelium of arteries, veins, capillaries, and lymphatics, and on syncytiotrophoblast of human placenta. J Cell Biol. 1985;101(2):363-71.

119 Light DR, Glaser CB, Betts M, Blasko E, Campbell E, Clarke JH, et al. The interaction of thrombomodulin with $\mathrm{Ca} 2+$. Eur J Biochem. 1999;262(2):522-33.

120 Adams TE, Huntington JA. Thrombin-cofactor interactions: structural insights into regulatory mechanisms. Arterioscler Thromb Vasc Biol. 2006;26(8):1738-45.

121 Marcus AJ, Broekman MJ, Drosopoulos JH Islam N, Pinsky DJ, Sesti C, et al. Heterologous cell-cell interactions: thromboregulation, cerebroprotection and cardioprotection by CD39 (NTPDase-1). J Thromb Haemost. 2003;1(12):2497-509.

122 Robson SC, Sévigny J, Zimmermann H. The E-NTPDase family of ectonucleotidases: Structure function relationships and pathophysiological significance. Purinergic Signal. 2006;2(2):409-30. 
123 Yau JW, Teoh H, Verma S. Endothelial cell control of thrombosis. BMC Cardiovasc Disord. 2015;15:130.

124 Straub AC, Butcher JT, Billaud M, Mutchler $\mathrm{SM}$, Artamonov MV, Nguyen AT, et al. Hemoglobin $\alpha /$ eNOS coupling at myoendothelial junctions is required for nitric oxide scavenging during vasoconstriction. Arterioscler Thromb Vasc Biol. 2014;34(12): 2594-600.

125 Straub AC, Lohman AW, Billaud M, Johnstone SR, Dwyer ST, Lee MY, et al. Endothelial cell expression of haemoglobin a regulates nitric oxide signalling. Nature. 2012; 491(7424):473-7.

126 Sandow SL, Gzik DJ, Lee RM. Arterial internal elastic lamina holes: relationship to function? J Anat. 2009;214(2):258-66.

127 Wong LC, Langille BL. Developmental remodeling of the internal elastic lamina of rabbit arteries: effect of blood flow. Circ Res. 1996;78(5):799-805.

128 Sonkusare SK, Dalsgaard T, Bonev AD, HillEubanks DC, Kotlikoff MI, Scott JD, et al. AKAP150-dependent cooperative TRPV4 channel gating is central to endothelium-dependent vasodilation and is disrupted in hypertension. Sci Signal. 2014;7(333):ra66.

129 Ottolini M, Hong K, Sonkusare SK. Calcium signals that determine vascular resistance. Wiley Interdiscip Rev Syst Biol Med. 2019; 11(5):e1448.

130 Biwer LA, Good ME, Hong K, Patel RK, Agrawal N, Looft-Wilson R, et al. Non-endoplasmic reticulum-based calr (calreticulin) can coordinate heterocellular calcium signaling and vascular function. Arterioscler Thromb Vasc Biol. 2018;38(1):120-30.

131 Hong K, Cope EL, DeLalio LJ, Marziano C, Isakson BE, Sonkusare SK. TRPV4 (transient receptor potential vanilloid 4) channeldependent negative feedback mechanism regulates $\mathrm{Gq}$ protein-coupled receptor-induced vasoconstriction. Arterioscler Thromb Vasc Biol. 2018;38(3):542-54.

132 Isakson BE, Ramos SI, Duling BR. Ca2+ and inositol 1,4,5-trisphosphate-mediated signaling across the myoendothelial junction. Circ Res. 2007;100(2):246-54.

133 Isakson BE. Localized expression of an Ins $(1,4,5) \mathrm{P} 3$ receptor at the myoendothelial junction selectively regulates heterocellular Ca2+ communication. J Cell Sci. 2008; 121(Pt 21):3664-73.

134 Dora KA, Sandow SL, Gallagher NT, Takano H, Rummery NM, Hill CE, et al. Myoendothelial gap junctions may provide the pathway for EDHF in mouse mesenteric artery. J Vasc Res. 2003;40(5):480-90.

135 Di Russo J, Luik AL, Yousif L, Budny S, Oberleithner H, Hofschröer V, et al. Endothelial basement membrane laminin 511 is essential for shear stress response. EMBO J. 2017;36(2):183-201.

136 Humphries JD, Byron A, Humphries MJ. Integrin ligands at a glance. J Cell Sci. 2006; 119(Pt 19):3901-3.
137 Zhou X, Rowe RG, Hiraoka N, George JP, Wirtz D, Mosher DF, et al. Fibronectin fibrillogenesis regulates three-dimensional neovessel formation. Genes Dev. 2008;22(9): 1231-43.

138 Stratman AN, Davis GE. Endothelial cellpericyte interactions stimulate basement membrane matrix assembly: influence on vascular tube remodeling, maturation, and stabilization. Microsc Microanal. 2012; 18(1):68-80.

139 Clifford PS, Ella SR, Stupica AJ, Nourian Z, Li M, Martinez-Lemus LA, et al. Spatial distribution and mechanical function of elastin in resistance arteries: a role in bearing longitudinal stress. Arterioscler Thromb Vasc Biol. 2011;31(12):2889-96.

140 Bloksgaard M, Leurgans TM, Nissen I, Jensen PS, Hansen ML, Brewer JR, et al. Elastin organization in pig and cardiovascular disease patients' pericardial resistance arteries. J Vasc Res. 2015;52(1):1-11.

141 Fischer GM, Llaurado JG. Collagen and elastin content in canine arteries selected from functionally different vascular beds. Circ Res. 1966;19(2):394-9.

142 Schwartz E, Adamany AM, Blumenfeld OO. Isolation and characterization of the internal elastic lamina from calf thoracic aorta. Exp Mol Pathol. 1981;34(3):299-306.

143 Lee RM. Morphology of cerebral arteries. Pharmacol Ther. 1995;66(1):149-73.

144 Harkness ML, Harkness RD, McDonald DA. The collagen and elastin content of the arterial wall in the dog. Proc R Soc Lond B Biol Sci. 1957;146(925):541-51.

145 Dobrin PB. Mechanical properties of arteries. Physiol Rev. 1978;58(2):397-460.

146 Lin CJ, Staiculescu MC, Hawes JZ, Cocciolone AJ, Hunkins BM, Roth RA, et al. Heterogeneous cellular contributions to elastic laminae formation in arterial wall development. Circ Res. 2019;125(11):1006-18.

147 Unemori EN, Bouhana KS, Werb Z. Vectorial secretion of extracellular matrix proteins, matrix-degrading proteinases, and tissue inhibitor of metalloproteinases by endothelial cells. J Biol Chem. 1990;265(1): 445-51.

148 Carnes WH, Abraham PA, Buonassisi V. Biosynthesis of elastin by an endothelial cell culture. Biochem Biophys Res Commun. 1979;90(4):1393-9.

149 Cantor JO, Keller S, Parshley MS, Darnule TV, Darnule AT, Cerreta JM, et al. Synthesis of crosslinked elastin by an endothelial cell culture. Biochem Biophys Res Commun. 1980;95(4):1381-6.

150 Damiano V, Tsang A, Weinbaum G, Christner P, Rosenbloom J. Secretion of elastin in the embryonic chick aorta as visualized by immunoelectron microscopy. Coll Relat Res. 1984;4(2):153-64.

151 Myers PR, Tanner MA. Vascular endothelial cell regulation of extracellular matrix collagen: role of nitric oxide. Arterioscler Thromb Vasc Biol. 1998;18(5):717-22.
152 Sechler JL, Corbett SA, Wenk MB, Schwarzbauer JE. Modulation of cell-extracellular matrix interactions. Ann N Y Acad Sci. 1998; 857:143-54.

153 Rohwedder I, Montanez E, Beckmann K, Bengtsson E, Dunér P, Nilsson J, et al. Plasma fibronectin deficiency impedes atherosclerosis progression and fibrous cap formation. EMBO Mol Med. 2012;4(7):564-76.

154 Rhodin JA. The ultrastructure of mammalian arterioles and precapillary sphincters. J Ultrastruct Res. 1967;18(1):181-223.

155 Sandow SL, Hill CE. Incidence of myoendothelial gap junctions in the proximal and distal mesenteric arteries of the rat is suggestive of a role in endothelium-derived hyperpolarizing factor-mediated responses. Circ Res. 2000;86(3):341-6.

156 Maarouf N, Sancho M, Fürstenhaupt T, Tran CH, Welsh DG. Structural analysis of endothelial projections from mesenteric arteries. Microcirculation. 2017;24(3).

157 Michel RP, Hu F, Meyrick BO. Myoendothelial junctional complexes in postobstructive pulmonary vasculopathy: a quantitative electron microscopic study. Exp Lung Res. 1995;21(3):437-52.

158 Shimokawa H, Yasutake H, Fujii K, Owada MK, Nakaike R, Fukumoto Y, et al. The importance of the hyperpolarizing mechanism increases as the vessel size decreases in endothelium-dependent relaxations in rat mesenteric circulation. J Cardiovasc Pharmacol. 1996;28(5):703-11.

159 Sandow SL, Neylon CB, Chen MX, Garland CJ. Spatial separation of endothelial smalland intermediate-conductance calcium-activated potassium channels $(\mathrm{K}(\mathrm{Ca}))$ and connexins: possible relationship to vasodilator function? J Anat. 2006;209(5):689-98.

160 Crane GJ, Gallagher N, Dora KA, Garland CJ. Small- and intermediate-conductance calcium-activated $\mathrm{K}+$ channels provide different facets of endothelium-dependent hyperpolarization in rat mesenteric artery. Physiol. 2003;553(Pt 1):183-9.

161 Crane GJ, Walker SD, Dora KA, Garland CJ. Evidence for a differential cellular distribution of inward rectifier $\mathrm{K}$ channels in the rat isolated mesenteric artery. J Vasc Res. 2003; 40(2):159-68.

162 Duling BR. Effects of potassium ion on the microcirculation of the hamster. Circ Res. 1975;37(3):325-32.

163 Knot HJ, Zimmermann PA, Nelson MT. Extracellular $\mathrm{K}(+)$-induced hyperpolarizations and dilatations of rat coronary and cerebral arteries involve inward rectifier $\mathrm{K}(+)$ channels. J Physiol. 1996;492(2Pt 2):419-30.

164 Harraz OF, Longden TA, Dabertrand F, Hill-Eubanks D, Nelson MT. Endothelial GqPCR activity controls capillary electrical signaling and brain blood flow through PIP(2) depletion. Proc Natl Acad Sci U S A. 2018;115(15):E3569-77. 
165 Eichler I, Wibawa J, Grgic I, Knorr A, Brakemeier S, Pries AR, et al. Selective blockade of endothelial Ca2+-activated small- and intermediate-conductance $\mathrm{K}+$-channels suppresses EDHF-mediated vasodilation. $\mathrm{Br} \mathrm{J}$ Pharmacol. 2003;138(4):594-601.

166 Gaete PS, Lillo MA, Ardiles NM, Pérez FR, Figueroa XF. Ca2+-activated $\mathrm{K}+$ channels of small and intermediate conductance control eNOS activation through $\mathrm{NAD}(\mathrm{P}) \mathrm{H}$ oxidase. Free Radic Biol Med. 2012;52(5):86070.

167 Isakson BE, Best AK, Duling BR. Incidence of protein on actin bridges between endothelium and smooth muscle in arterioles demonstrates heterogeneous connexin expression and phosphorylation. Am J Physiol Heart Circ Physiol. 2008;294(6):H2898904.

168 Beyer S, Kelly RG, Miquerol L. Inducible Cx40-Cre expression in the cardiac conduction system and arterial endothelial cells. Genesis. 2011;49(2):83-91.

169 Mather S, Dora KA, Sandow SL, Winter P, Garland CJ. Rapid endothelial cell-selective loading of connexin 40 antibody blocks endothelium-derived hyperpolarizing factor dilation in rat small mesenteric arteries. Circ Res. 2005;97(4):399-407.

170 Chaytor AT, Evans WH, Griffith TM. Central role of heterocellular gap junctional communication in endothelium-dependent relaxations of rabbit arteries. J Physiol. 1998; 508(Pt 2):561-73.

171 Segal SS, Duling BR. Conduction of vasomotor responses in arterioles: a role for cell-tocell coupling? Am J Physiol. 1989;256(3 Pt 2): $\mathrm{H} 838-45$

172 Yashiro Y, Duling BR. Integrated Ca2+ signaling between smooth muscle and endothelium of resistance vessels. Circ Res. 2000; 87(11):1048-54.

173 Dora KA, Doyle MP, Duling BR. Elevation of intracellular calcium in smooth muscle causes endothelial cell generation of NO in arterioles. Proc Natl Acad Sci U S A. 1997; 94(12):6529-34.

174 Tran CH, Taylor MS, Plane F, Nagaraja S, Tsoukias NM, Solodushko V, et al. Endothelial $\mathrm{Ca} 2+$ wavelets and the induction of myoendothelial feedback. Am J Physiol, Cell Physiol. 2012;302(8):C1226-42.

175 Kerr PM, Tam R, Ondrusova K, Mittal R, Narang D, Tran CH, et al. Endothelial feedback and the myoendothelial projection. Microcirculation. 2012;19(5):416-22.

176 Lemmey HAL, Garland CJ, Dora KA. Intrinsic regulation of microvascular tone by myoendothelial feedback circuits. Curr Top Membr. 2020;85:327-55.

177 Garland CJ, Bagher P, Powell C, Ye X, Lemmey HAL, Borysova L, et al. Voltage-dependent $\mathrm{Ca} 2+$ entry into smooth muscle during contraction promotes endothelium-mediated feedback vasodilation in arterioles. Sci Signal. 2017;10(486):eaal3806.
178 Sakai H, Hara H, Tsai AG, Tsuchida E, Intaglietta M. Constriction of resistance arteries determines 1-NAME-induced hypertension in a conscious hamster model. Microvasc Res. 2000;60(1):21-7.

179 Budel S, Bartlett IS, Segal SS. Homocellular conduction along endothelium and smooth muscle of arterioles in hamster cheek pouch: unmasking an NO wave. Circ Res. 2003; 93(1):61-8.

180 Hakim TS, Sugimori K, Camporesi EM, Anderson G. Half-life of nitric oxide in aqueous solutions with and without haemoglobin. Physiol Meas. 1996;17(4):267-77.

181 Keller TC, Butcher JT, Broseghini-Filho GB, Marziano C, DeLalio LJ, Rogers S, et al. Modulating vascular hemodynamics with an alpha globin mimetic peptide (HbalphaX). Hypertension. 2016;68(6):1494-503.

182 Butcher JT, Johnson T, Beers J, Columbus L, Isakson BE. Hemoglobin $\alpha$ in the blood vessel wall. Free Radic Biol Med. 2014;73:13642.

183 Garcia V, Park EJ, Siragusa M, Frohlich F, Mahfuzul Haque M, Pascale JV, et al. Unbiased proteomics identifies plasminogen activator inhibitor-1 as a negative regulator of endothelial nitric oxide synthase. Proc Natl Acad Sci U S A. 2020;117(17):9497-507.

184 Leo F, Hutzler B, Ruddiman CA, Isakson BE, Cortese-Krott MM. Cellular microdomains for nitric oxide signaling in endothelium and red blood cells. Nitric Oxide. 2020 Mar 1;96:44-53.

185 Biwer LA, Isakson BE. Endoplasmic reticulum-mediated signalling in cellular microdomains. Acta Physiol. 2017;219(1):162-75.

186 Ledoux J, Taylor MS, Bonev AD, Hannah RM, Solodushko V, Shui B, et al. Functional architecture of inositol 1,4,5-trisphosphate signaling in restricted spaces of myoendothelial projections. Proc Natl Acad Sci U S A. 2008;105(28):9627-32.

187 Uehara K. Localization of TRPC1 channel in the sinus endothelial cells of rat spleen. Histochem Cell Biol. 2005;123(4-5):347-56.

188 Wilson C, Lee MD, Heathcote HR, Zhang X, Buckley C, Girkin JM, et al. Mitochondrial ATP production provides long-range control of endothelial inositol trisphosphateevoked calcium signaling. J Biol Chem. 2019; 294(3):737-58.

189 Heberlein KR, Straub AC, Best AK, Greyson MA, Looft-Wilson RC, Sharma PR, et al. Plasminogen activator inhibitor-1 regulates myoendothelial junction formation. Circ Res. 2010;106(6):1092-102.

190 Heberlein KR, Han J, Straub AC, Best AK, Kaun C, Wojta J, et al. A novel mRNA binding protein complex promotes localized plasminogen activator inhibitor- 1 accumulation at the myoendothelial junction. Arterioscler Thromb Vasc Biol. 2012;32(5): 1271-9.
191 McCallinhart PE, Biwer LA, Clark OE, Isakson BE, Lilly B, Trask AJ. Myoendothelial junctions of mature coronary vessels express notch signaling proteins. Front Physiol. 2020;11:29.

192 Carnegie GK, Means CK, Scott JD. A-kinase anchoring proteins: from protein complexes to physiology and disease. IUBMB Life. 2009;61(4):394-406.

193 Langeberg LK, Scott JD. Signalling scaffolds and local organization of cellular behaviour. Nat Rev Mol Cell Biol. 2015;16(4):232-44.

194 Carr DW, Stofko-Hahn RE, Fraser ID, Bishop SM, Acott TS, Brennan RG, et al. Interaction of the regulatory subunit (RII) of cAMP-dependent protein kinase with RIIanchoring proteins occurs through an amphipathic helix binding motif. J Biol Chem. 1991;266(22):14188-92.

195 Klauck TM, Faux MC, Labudda K, Langeberg LK, Jaken S, Scott JD. Coordination of three signaling enzymes by AKAP79, a mammalian scaffold protein. Science. 1996; 271(5255):1589-92.

196 Coghlan VM, Perrino BA, Howard M, Langeberg LK, Hicks JB, Gallatin WM, et al. Association of protein kinase $\mathrm{A}$ and protein phosphatase $2 \mathrm{~B}$ with a common anchoring protein. Science. 1995;267(5194):108-11.

197 Scott JD, Dessauer CW, Taskén K. Creating order from chaos: cellular regulation by kinase anchoring. Annu Rev Pharmacol Toxicol. 2013;53:187-210.

198 Schiattarella GG, Cattaneo F, Carrizzo A, Paolillo R, Boccella N, Ambrosio M, et al Akap1 regulates vascular function and endothelial cells behavior. Hypertension. 2018; 71(3):507-17.

199 Motawea HK, Blazek AD, Zirwas MJ, Pleister AP, Ahmed AA, McConnell BK, et al. Delocalization of endogenous A-kinase antagonizes Rap1-Rho- $\alpha$. J Cytol Mol Biol. 2014;1(1)

200 Mercado J, Baylie R, Navedo MF, Yuan C, Scott JD, Nelson MT, et al. Local control of TRPV4 channels by AKAP150-targeted PKC in arterial smooth muscle. J Gen Physiol. 2014;143(5):559-75.

201 Diviani D, Reggi E, Arambasic M, Caso S, Maric D. Emerging roles of A-kinase anchoring proteins in cardiovascular pathophysiology. Biochim Biophys Acta. 2016; 1863(7 Pt B):1926-36.

202 Radeva MY, Kugelmann D, Spindler V, Waschke J. PKA compartmentalization via AKAP220 and AKAP12 contributes to endothelial barrier regulation. PLoS One. 2014;9(9):e106733.

203 Kwon HB, Choi YK, Lim JJ, Kwon SH, Her $\mathrm{S}$, Kim HJ, et al. AKAP12 regulates vascular integrity in zebrafish. Exp Mol Med. 2012; 44(3):225-35.

204 Malinin NL, Pluskota E, Byzova TV. Integrin signaling in vascular function. Curr Opin Hematol. 2012;19(3):206-11.

205 Akiyama SK. Integrins in cell adhesion and signaling. Hum Cell. 1996;9(3):181-6. 
206 Bhullar IS, Li YS, Miao H, Zandi E, Kim M, Shyy JY, et al. Fluid shear stress activation of IkappaB kinase is integrin-dependent. J Biol Chem. 1998;273(46):30544-9.

207 Dejana ECG, Zanetti A, Lampugnani MG, Marchisio PC. Receptors for extracellular matrix proteins in endothelial cells. In: Catravas JDGCN, Ryan US, editors. Vascular endothelium. Boston, MA: Springer; 1989. p. 141-7.

208 Welser-Alves JV, Boroujerdi A, Tigges U, Wrabetz L, Feltri ML, Milner R. Endothelial beta4 integrin is predominantly expressed in arterioles, where it promotes vascular remodeling in the hypoxic brain. Arterioscler Thromb Vasc Biol. 2013;33(5):943-53.

209 Goyer B, Thériault M, Gendron SP, Brunette I, Rochette PJ, Proulx S. Extracellular matrix and integrin expression profiles in Fuchs endothelial corneal dystrophy cells and tissue model. Tissue Eng Part A. 2018;24(7-8): 607-15.

210 Choi JS, Kim EY, Kim MJ, Giegengack M, Khan FA, Khang G, et al. In vitro evaluation of the interactions between human corneal endothelial cells and extracellular matrix proteins. Biomed Mat. 2013;8(1):014108.

211 Lampugnani MG, Resnati M, Dejana E, Marchisio PC. The role of integrins in the maintenance of endothelial monolayer integrity. J Cell Biol. 1991;112(3):479-90.

212 Pelletier AJ, Kunicki T, Ruggeri ZM, Quaranta $\mathrm{V}$. The activation state of the integrin alpha IIb beta 3 affects outside-in signals leading to cell spreading and focal adhesion kinase phosphorylation. J Biol Chem. 1995; 270(30):18133-40.

213 Petzold T, Orr AW, Hahn C, Jhaveri KA, Parsons JT, Schwartz MA. Focal adhesion kinase modulates activation of NF-kappaB by flow in endothelial cells. Am J Physiol Cell Physiol. 2009;297(4):C814-22.

214 Li S, Kim M, Hu YL, Jalali S, Schlaepfer DD, Hunter T, et al. Fluid shear stress activation of focal adhesion kinase. Linking to mitogen-activated protein kinases. J Biol Chem. 1997;272(48):30455-62.

215 Feaver RE, Gelfand BD, Wang C, Schwartz MA, Blackman BR. Atheroprone hemodynamics regulate fibronectin deposition to create positive feedback that sustains endothelial inflammation. Circ Res. 2010; 106(11):1703-11.

216 Diaz C, Neubauer S, Rechenmacher F, Kessler H, Missirlis D. Recruitment of alphanubeta3 integrin to alpha5beta1 integrin-induced clusters enables focal adhesion maturation and cell spreading. J Cell Sci. 2020; 133(1):jcs232702.

217 Moon JJ, Matsumoto M, Patel S, Lee L, Guan JL, Li S. Role of cell surface heparan sulfate proteoglycans in endothelial cell migration and mechanotransduction. J Cell Physiol. 2005;203(1):166-76.
218 Schiller HB, Hermann MR, Polleux J, Vignaud T, Zanivan S, Friedel CC, et al. Beta1and alphav-class integrins cooperate to regulate myosin II during rigidity sensing of fibronectin-based microenvironments. Nat Cell Biol. 2013;15(6):625-36.

219 Missirlis D, Haraszti T, Scheele C, Wiegand T, Diaz C, Neubauer S, et al. Substrate engagement of integrins alpha5betal and alphavbeta 3 is necessary, but not sufficient, for high directional persistence in migration on fibronectin. Sci Rep. 2016;6:23258.

220 Cines DB, Pollak ES, Buck CA, Loscalzo J, Zimmerman GA, McEver RP, et al. Endothelial cells in physiology and in the pathophysiology of vascular disorders. Blood. 1998;91(10):3527-61.

221 Wei H, Sundararaman A, Dickson E, Rennie-Campbell L, Cross E, Heesom KJ, et al. Characterization of the polarized endothelial secretome. FASEB J. 2019;33(11):1227787.

222 Burghoff S, Schrader J. Secretome of human endothelial cells under shear stress. J Proteome Res. 2011;10(3):1160-9.

223 Cho JS, Ouriel K. Differential thrombogenicity of artery and vein: the role of von Willebrand factor. Ann Vasc Surg. 1995;9(1): 60-70.

224 Mohr T, Haudek-Prinz V, Slany A, Grillari J, Micksche M, Gerner C. Proteome profiling in IL-1beta and VEGF-activated human umbilical vein endothelial cells delineates the interlink between inflammation and angiogenesis. PLoS One. 2017;12(6):e0179065.

225 Zanivan S, Maione F, Hein MY, HernandezFernaud JR, Ostasiewicz P, Giraudo E, et al. SILAC-based proteomics of human primary endothelial cell morphogenesis unveils tumor angiogenic markers. Mol Cell Proteomics. 2013;12(12):3599-611.

226 Epelman S, Tang WH, Chen SY, Van Lente F, Francis GS, Sen S. Detection of soluble angiotensin-converting enzyme 2 in heart failure: insights into the endogenous counter-regulatory pathway of the renin-angiotensin-aldosterone system. J Am Coll Cardiol. 2008;52(9):750-4.

227 Zerwes HG, Risau W. Polarized secretion of a platelet-derived growth factor-like chemotactic factor by endothelial cells in vitro. J Cell Biol. 1987;105(5):2037-41.

228 Tada S, Tarbell JM. Internal elastic lamina affects the distribution of macromolecules in the arterial wall: a computational study. Am J Physiol Heart Circ Physiol. 2004;287(2): H905-13.

229 Sporn LA, Marder VJ, Wagner DD. Differing polarity of the constitutive and regulated secretory pathways for von Willebrand factor in endothelial cells. J Cell Biol. 1989; 108(4):1283-9.

230 Platt JL, Vercellotti GM, Lindman BJ, Oegema TR Jr, Bach FH, Dalmasso AP. Release of heparan sulfate from endothelial cells. Implications for pathogenesis of hyperacute rejection. J Exp Med. 1990;171(4):1363-8.
231 Wagner OF, Christ G, Wojta J, Vierhapper $\mathrm{H}$, Parzer S, Nowotny PJ, et al. Polar secretion of endothelin- 1 by cultured endothelial cells. J Biol Chem. 1992;267(23):16066-8.

232 Russell FD, Davenport AP. Secretory pathways in endothelin synthesis. Br J Pharmacol. 1999;126(2):391-8.

233 Desideri G, Ferri C, Bellini C, De Mattia G, Santucci A. Effects of ACE inhibition on spontaneous and insulin-stimulated endothelin-1 secretion: in vitro and in vivo studies. Diabetes. 1997;46(1):81-6.

234 Upchurch GR Jr, Banes AJ, Wagner WH, Ramadan F, Link GW, Henderson RH, et al. Differences in secretion of prostacyclin by venous and arterial endothelial cells grown in vitro in a static versus a mechanically active environment. J Vasc Surg. 1989;10(3):292-8.

235 Wallez Y, Huber P. Endothelial adherens and tight junctions in vascular homeostasis, inflammation and angiogenesis. Biochim Biophys Acta. 2008;1778(3):794-809.

236 Lampugnani MG. Endothelial cell-to-cell junctions: adhesion and signaling in physiology and pathology. Cold Spring Harb Perspect Med. 2012;2(10):a006528.

237 Simionescu M, Simionescu N, Palade GE Segmental differentiations of cell junctions in the vascular endothelium. The microvasculature. J Cell Biol. 1975;67(3):863-85.

238 Simionescu M, Simionescu N, Palade GE. Segmental differentiations of cell junctions in the vascular endothelium. Arteries and veins. J Cell Biol. 1976;68(3):705-23.

239 Kniesel U, Risau W, Wolburg H. Development of blood-brain barrier tight junctions in the rat cortex. Brain Res Dev Brain Res. 1996;96(1-2):229-40.

240 Millan J, Cain RJ, Reglero-Real N, Bigarella C, Marcos-Ramiro B, Fernandez-Martin L, et al. Adherens junctions connect stress fibres between adjacent endothelial cells. BMC Biol. 2010;8:11.

241 Curry FR. Microvascular solute and water transport. Microcirculation. 2005;12(1):1731.

242 Taddei A, Giampietro C, Conti A, Orsenigo F, Breviario F, Pirazzoli V, et al. Endothelial adherens junctions control tight junctions by VE-cadherin-mediated upregulation of claudin-5. Nat Cell Biol. 2008;10(8):923-34.

243 Nieset JE, Redfield AR, Jin F, Knudsen KA, Johnson KR, Wheelock MJ. Characterization of the interactions of alpha-catenin with alpha-actinin and beta-catenin/plakoglobin. J Cell Sci. 1997;110(Pt 8):1013-22.

244 Knudsen KA, Soler AP, Johnson KR, Wheelock MJ. Interaction of alpha-actinin with the cadherin/catenin cell-cell adhesion complex via alpha-catenin. J Cell Biol. 1995; 130(1):67-77.

245 Venkiteswaran K, Xiao K, Summers S, Calkins CC, Vincent PA, Pumiglia K, et al. Regulation of endothelial barrier function and growth by VE-cadherin, plakoglobin, and beta-catenin. Am J Physiol Cell Physiol. 2002;283(3):C811-21. 
246 Franke WW, Kapprell HP, Cowin P. Immunolocalization of plakoglobin in endothelial junctions: identification as a special type of Zonulae adhaerentes. Biol Cell. 1987;59(3): 205-18.

247 Navarro P, Ruco L, Dejana E. Differential localization of VE- and N-cadherins in human endothelial cells: VE-cadherin competes with $\mathrm{N}$-cadherin for junctional localization. J Cell Biol. 1998;140(6):1475-84.

248 Salomon D, Ayalon O, Patel-King R, Hynes RO, Geiger B. Extrajunctional distribution of $\mathrm{N}$-cadherin in cultured human endothelial cells. J Cell Sci. 1992;102(Pt 1):7-17.

249 Orsenigo F, Giampietro C, Ferrari A, Corada M, Galaup A, Sigismund S, et al. Phosphorylation of VE-cadherin is modulated by haemodynamic forces and contributes to the regulation of vascular permeability in vivo. Nat Commun. 2012;3:1208.

250 Kiosses WB, McKee NH, Kalnins VI. The distribution of centrosomes in endothelial cells of the rat aorta and inferior vena cava. Artery. 1997;22(5):251-65.

251 Baumer S, Keller L, Holtmann A, Funke R, August B, Gamp A, et al. Vascular endothelial cell-specific phosphotyrosine phosphatase (VE-PTP) activity is required for blood vessel development. Blood. 2006;107(12): 4754-62.

252 Dominguez MG, Hughes VC, Pan L, Simmons M, Daly C, Anderson K, et al. Vascular endothelial tyrosine phosphatase (VEPTP)-null mice undergo vasculogenesis but die embryonically because of defects in angiogenesis. Proc Natl Acad Sci U S A. 2007; 104(9):3243-8.

253 Nawroth R, Poell G, Ranft A, Kloep S, Samulowitz U, Fachinger G, et al. VE-PTP and VE-cadherin ectodomains interact to facilitate regulation of phosphorylation and cell contacts. EMBO J. 2002;21(18):4885-95.

254 Shaw SK, Bamba PS, Perkins BN, Luscinskas FW. Real-time imaging of vascular endothelial-cadherin during leukocyte transmigration across endothelium. J Immunol. 2001; 167(4):2323-30.

255 Esser S, Lampugnani MG, Corada M, Dejana E, Risau W. Vascular endothelial growth factor induces VE-cadherin tyrosine phosphorylation in endothelial cells. J Cell Sci. 1998;111(Pt 13):1853-65.

256 Wagner R, Kachar B. Linear gap and tight junctional assemblies between capillary endothelial cells in the eel rete mirabile. Anat Rec. 1995;242(4):545-52.

257 Meens MJ, Alonso F, Le Gal L, Kwak BR, Haefliger JA. Endothelial Connexin 37 and Connexin 40 participate in basal but not agonist-induced NO release. Cell Commun Signal. 2015;13:34.

258 Hwan Seul K, Beyer EC. Heterogeneous localization of connexin 40 in the renal vasculature. Microvasc Res. 2000;59(1):140-8.
259 Figueroa XF, Paul DL, Simon AM, Goodenough DA, Day KH, Damon DN, et al. Central role of connexin 40 in the propagation of electrically activated vasodilation in mouse cremasteric arterioles in vivo. Circ Res. 2003; 92(7):793-800.

260 de Wit C, Roos F, Bolz SS, Kirchhoff S, Kruger $\mathrm{O}$, Willecke $\mathrm{K}$, et al. Impaired conduction of vasodilation along arterioles in connexin40-deficient mice. Circ Res. 2000; 86(6):649-55.

261 Isakson BE, Damon DN, Day KH, Liao Y, Duling BR. Connexin 40 and connexin 43 in mouse aortic endothelium: evidence for $\mathrm{CO}_{-}$ ordinated regulation. Am J Physiol Heart Circ Physiol. 2006;290(3):H1199-205.

262 Sandow SL, Looft-Wilson R, Doran B, Grayson TH, Segal SS, Hill CE. Expression of homocellular and heterocellular gap junctions in hamster arterioles and feed arteries. Cardiovasc Res. 2003;60(3):643-53.

263 Hakim CH, Jackson WF, Segal SS. Connexin isoform expression in smooth muscle cells and endothelial cells of hamster cheek pouch arterioles and retractor feed arteries. Microcirculation. 2008;15(6):503-14.

264 van Kempen MJ, Jongsma HJ. Distribution of connexin 37 , connexin 40 and connexin 43 in the aorta and coronary artery of several mammals. Histochem Cell Biol. 1999; 112(6):479-86.

265 Yeh HI, Dupont E, Coppen S, Rothery S, Severs NJ. Gap junction localization and connexin expression in cytochemically identified endothelial cells of arterial tissue. J Histochem Cytochem. 1997;45(4):539-50.

266 Gabriels JE, Paul DL. Connexin43 is highly localized to sites of disturbed flow in rat aortic endothelium but connexin 37 and connexin40 are more uniformly distributed. Circ Res. 1998;83(6):636-43.

267 Yeh HI, Lu CS, Wu YJ, Chen CC, Hong RC, Ko YS, et al. Reduced expression of endothelial connexin 37 and connexin 40 in hyperlipidemic mice: recovery of connexin 37 after 7-day simvastatin treatment. Arterioscler Thromb Vasc Biol. 2003;23(8):1391-7.

268 Boittin FX, Alonso F, Le Gal L, Allagnat F, Beny JL, Haefliger JA. Connexins and M3 muscarinic receptors contribute to heterogeneous $\mathrm{Ca} 2+$ signaling in mouse aortic endothelium. Cell Physiol Biochem. 2013; 31(1):166-78

269 Munger SJ, Kanady JD, Simon AM. Absence of venous valves in mice lacking Connexin37. Dev Biol. 2013;373(2):338-48.

270 Johnstone S, Isakson B, Locke D. Biological and biophysical properties of vascular connexin channels. Int Rev Cell Mol Biol. 2009; 278:69-118.

271 Muller WA, Weigl SA, Deng X, Phillips DM. PECAM-1 is required for transendothelial migration of leukocytes. J Exp Med. 1993; 178(2):449-60.
272 Tzima E, Irani-Tehrani M, Kiosses WB, Dejana E, Schultz DA, Engelhardt B, et al. A mechanosensory complex that mediates the endothelial cell response to fluid shear stress. Nature. 2005;437(7057):426-31.

273 Schenkel AR, Mamdouh Z, Chen X, Liebman RM, Muller WA. CD99 plays a major role in the migration of monocytes through endothelial junctions. Nat Immunol. 2002; 3(2):143-50.

274 Bardin N, Anfosso F, Masse JM, Cramer E, Sabatier F, Le Bivic A, et al. Identification of CD146 as a component of the endothelial junction involved in the control of cell-cell cohesion. Blood. 2001;98(13):3677-84.

275 Yamamoto H, Ehling M, Kato K, Kanai K, van Lessen $M$, Frye $M$, et al. Integrin beta1 controls VE-cadherin localization and blood vessel stability. Nat Commun. 2015;6:6429.

276 Sehrawat S, Ernandez T, Cullere X, Takahashi M, Ono Y, Komarova Y, et al. AKAP9 regulation of microtubule dynamics promotes Epac1-induced endothelial barrier properties. Blood. 2011;117(2):708-18.

277 Chidlow JH Jr, Sessa WC. Caveolae, caveolins, and cavins: complex control of cellular signalling and inflammation. Cardiovasc Res. 2010;86(2):219-25.

278 Saliez J, Bouzin C, Rath G, Ghisdal P, Desjardins F, Rezzani R, et al. Role of caveolar compartmentation in endothelium-derived hyperpolarizing factor-mediated relaxation: $\mathrm{Ca} 2+$ signals and gap junction function are regulated by caveolin in endothelial cells. Circulation. 2008;117(8):1065-74.

279 Segal SS, Brett SE, Sessa WC. Codistribution of NOS and caveolin throughout peripheral vasculature and skeletal muscle of hamsters. Am J Physiol. 1999;277(3):H1167-77.

280 Calizo RC, Scarlata S. A role for G-proteins in directing G-protein-coupled receptor-caveolae localization. Biochemistry. 2012; 51(47):9513-23.

281 Gosens R, Stelmack GL, Dueck G, Mutawe MM, Hinton M, McNeill KD, et al. Caveolae facilitate muscarinic receptor-mediated intracellular $\mathrm{Ca} 2+$ mobilization and contraction in airway smooth muscle. Am J Physiol Lung Cell Mol Physiol. 2007;293(6):L140618.

282 Ju H, Zou R, Venema VJ, Venema RC. Direct interaction of endothelial nitric-oxide synthase and caveolin-1 inhibits synthase activity. J Biol Chem. 1997;272(30):18522-5.

283 Fernández-Hernando C, Yu J, Suárez Y, Rahner C, Dávalos A, Lasunción MA, et al. Genetic evidence supporting a critical role of endothelial caveolin-1 during the progression of atherosclerosis. Cell Metab. 2009; 10(1):48-54.

284 Santibanez JF, Blanco FJ, Garrido-Martin EM, Sanz-Rodriguez F, del Pozo MA, Bernabeu C. Caveolin-1 interacts and cooperates with the transforming growth factor-beta type I receptor ALK1 in endothelial caveolae. Cardiovasc Res. 2008;77(4):791-9. 
285 Babitt J, Trigatti B, Rigotti A, Smart EJ, Anderson RG, Xu S, et al. Murine SR-BI, a high density lipoprotein receptor that mediates selective lipid uptake, is $\mathrm{N}$-glycosylated and fatty acylated and colocalizes with plasma membrane caveolae. J Biol Chem. 1997; 272(20):13242-9.

286 Goedicke-Fritz S, Kaistha A, Kacik M, Markert S, Hofmeister A, Busch C, et al. Evidence for functional and dynamic microcompartmentation of Cav-1/TRPV4/K(Ca) in caveolae of endothelial cells. Eur J Cell Biol. 2015;94(7-9):391-400.

287 Lu T, Wang XL, Chai Q, Sun X, Sieck GC, Katusic ZS, et al. Role of the endothelial caveolae microdomain in shear stress-mediated coronary vasorelaxation. J Biol Chem. 2017;292(46):19013-23.

288 Ottolini M, Hong K, Sonkusare SK. Calcium signals that determine vascular resistance. Wiley Interdiscip Rev Syst Biol Med. 2019; 11(5):e1448.

289 Mountian I, Manolopoulos VG, De Smedt H, Parys JB, Missiaen L, Wuytack F. Expression patterns of sarco/endoplasmic reticulum Ca2+-ATPase and inositol 1,4,5-trisphosphate receptor isoforms in vascular endothelial cells. Cell Calcium. 1999;25(5):371-80.

290 Grayson TH, Haddock RE, Murray TP, Wojcikiewicz RJ, Hill CE. Inositol 1,4,5-trisphosphate receptor subtypes are differentially distributed between smooth muscle and endothelial layers of rat arteries. Cell Calcium. 2004;36(6):447-58.

291 Lin Q, Zhao L, Jing R, Trexler C, Wang H, Li $\mathrm{Y}$, et al. Inositol 1,4,5-trisphosphate receptors in endothelial cells play an essential role in vasodilation and blood pressure regulation. J Am Heart Assoc. 2019;8(4):e011704.

292 Ledoux J, Taylor MS, Bonev AD, Hannah RM, Solodushko V, Shui B, et al. Functional architecture of inositol 1, 4, 5-trisphosphate signaling in restricted spaces of myoendothelial projections. Proc Natl Acad Sci U S A. 2008;105(28):9627-32.

293 Yuan Q, Yang J, Santulli G, Reiken SR, Wronska A, Kim MM, et al. Maintenance of normal blood pressure is dependent on IP3R1-mediated regulation of eNOS. Proc Natl Acad Sci U S A. 2016;113(30):8532-7.

294 Bagher P, Beleznai T, Kansui Y, Mitchell R, Garland CJ, Dora KA. Low intravascular pressure activates endothelial cell TRPV4 channels, local Ca2+ events, and IKCa channels, reducing arteriolar tone. Proc Natl Acad Sci U S A. 2012;109(44):18174-9.

295 Smith IF, Wiltgen SM, Parker I. Localization of puff sites adjacent to the plasma membrane: functional and spatial characterization of Ca2+ signaling in SH-SY5Y cells utilizing membrane-permeant caged IP3. Cell Calcium. 2009;45(1):65-76.

296 Geyer M, Huang F, Sun Y, Vogel SM, Malik $\mathrm{AB}$, Taylor CW, et al. Microtubule-Associated protein $\mathrm{EB} 3$ regulates IP3 receptor clustering and $\mathrm{Ca} 2+$ signaling in endothelial cells. Cell Rep. 2015;12(1):79-89.
297 Yap FC, Weber DS, Taylor MS, Townsley MI, Comer BS, Maylie J, et al. Endothelial SK3 channel-associated Ca2+ microdomains modulate blood pressure. Am J Physiol Heart Circ Physiol. 2016;310(9):H1151-63.

298 Murata T, Lin MI, Huang Y, Yu J, Bauer PM, Giordano FJ, et al. Reexpression of caveolin-1 in endothelium rescues the vascular, cardiac, and pulmonary defects in global caveolin-1 knockout mice. J Exp Med. 2007; 204(10):2373-82.

299 Lipowsky HH, Kovalcheck S, Zweifach BW. The distribution of blood rheological parameters in the microvasculature of cat mesentery. Circ Res. 1978;43(5):738-49.

300 Lipowsky HH, Usami S, Chien S. In vivo measurements of "apparent viscosity" and microvessel hematocrit in the mesentery of the cat. Microvasc Res. 1980;19(3):297-319.

301 Coan DE, Wechezak AR, Viggers RF, Sauvage LR. Effect of shear stress upon localization of the Golgi apparatus and microtubule organizing center in isolated cultured endothelial cells. J Cell Sci. 1993;104(4):1145-53.

302 Kwon H-B, Wang S, Helker CS, Rasouli SJ, Maischein H-M, Offermanns S, et al. In vivo modulation of endothelial polarization by Apelin receptor signalling. Nat Commun. 2016;7:11805.

303 Simmers MB, Pryor AW, Blackman BR. Arterial shear stress regulates endothelial celldirected migration, polarity, and morphology in confluent monolayers. Am J Physiol Heart Circ Physiol. 2007;293(3):H1937H46.

304 Dewey CF Jr, Bussolari SR, Gimbrone MA Jr, Davies PF. The dynamic response of vascular endothelial cells to fluid shear stress. J Biomech Eng. 1981;103(3):177-85.

305 Noria S, Cowan DB, Gotlieb AI, Langille BL. Transient and steady-state effects of shear stress on endothelial cell adherens junctions. Circ Res. 1999;85(6):504-14.

306 Tzima E, del Pozo MA, Shattil SJ, Chien S, Schwartz MA. Activation of integrins in endothelial cells by fluid shear stress mediates Rho-dependent cytoskeletal alignment. EMBO J. 2001;20(17):4639-47.

307 Tzima E, Kiosses WB, del Pozo MA, Schwartz MA. Localized cdc42 activation, detected using a novel assay, mediates microtubule organizing center positioning in endothelial cells in response to fluid shear stress. J Biol Chem. 2003;278(33):31020-3.

308 Li J, Hou B, Tumova S, Muraki K, Bruns A, Ludlow MJ, et al. Piezo1 integration of vascular architecture with physiological force. Nature. 2014;515(7526):279.

309 Perozo E. New structural perspectives on K+ channel gating. Structure. 2002;10(8): 1027-9.

310 Coon BG, Baeyens N, Han J, Budatha M, Ross TD, Fang JS, et al. Intramembrane binding of VE-cadherin to VEGFR2 and VEGFR3 assembles the endothelial mechanosensory complex. J Cell Biol. 2015;208(7): 975-86.
311 Jung B, Obinata H, Galvani S, Mendelson K, Ding B-s, Skoura A, et al. Flow-regulated endothelial S1P receptor-1 signaling sustains vascular development. Dev Cell. 2012;23(3): 600-10.

312 Zou Y, Akazawa H, Qin Y, Sano M, Takano $\mathrm{H}$, Minamino T, et al. Mechanical stress activates angiotensin II type 1 receptor without the involvement of angiotensin II. Nat Cell Biol. 2004;6(6):499.

313 Wang S, Iring A, Strilic B, Juárez JA, Kaur H, Troidl K, et al. P2Y 2 and G q/G 11 control blood pressure by mediating endothelial mechanotransduction. J Clin invest. 2015; 125(8):3077-86.

314 Lehtonen J, Kinnunen P. Phospholipase A2 as a mechanosensor. Biophy J. 1995;68(5): 1888-94.

315 Goetz JG, Steed E, Ferreira RR, Roth S, Ramspacher C, Boselli F, et al. Endothelial cilia mediate low flow sensing during zebrafish vascular development. Cell Rep. 2014 6(5):799-808.

316 Hierck BP, Van der Heiden K, Alkemade FE, Van de Pas S, Van Thienen JV, Groenendijk BC, et al. Primary cilia sensitize endothelial cells for fluid shear stress. Dev Dyn. 2008; 237(3):725-35.

317 Weinbaum S, Zhang X, Han Y, Vink H, Cowin SC. Mechanotransduction and flow across the endothelial glycocalyx. Proc Natl Acad Sci U S A. 2003;100(13):7988-95.

318 Tkachenko E, Gutierrez E, Saikin SK, Fogelstrand P, Kim C, Groisman A, et al. The nucleus of endothelial cell as a sensor of blood flow direction. Biol Open. 2013;2(10):100712 .

319 Davies PF. Flow-mediated endothelial mechanotransduction. Physiol Rev. 1995; 75(3):519-60.

320 Fang Y, Wu D, Birukov KG. Mechanosensing and mechanoregulation of endothelial cell functions. Compr Physiol. 2019;9(2): 873-904.

321 Ranade SS, Qiu Z, Woo SH, Hur SS, Murthy SE, Cahalan SM, et al. Piezo1, a mechanically activated ion channel, is required for vascular development in mice. Proc Natl Acad Sci U S A. 2014;111(28):10347-52.

322 Wang S, Chennupati R, Kaur H, Iring A, Wettschureck N, Offermanns S. Endothelial cation channel PIEZO1 controls blood pressure by mediating flow-induced ATP release. J Clin Invest. 2016;126(12):4527-36.

323 Conway DE, Breckenridge MT, Hinde E, Gratton E, Chen CS, Schwartz MA. Fluid shear stress on endothelial cells modulates mechanical tension across VE-cadherin and PECAM-1. Curr Biol. 2013;23(11):1024-30.

324 Osawa M, Masuda M, Kusano K, Fujiwara $\mathrm{K}$. Evidence for a role of platelet endothelial cell adhesion molecule-1 in endothelial cell mechanosignal transduction: is it a mechanoresponsive molecule? J Cell Biol. 2002; 158(4):773-85. 
325 Chiu YJ, McBeath E, Fujiwara K. Mechanotransduction in an extracted cell model: Fyn drives stretch- and flow-elicited PECAM-1 phosphorylation. J Cell Biol. 2008;182(4): 753-63.

326 Duncan GS, Andrew DP, Takimoto $\mathrm{H}$, Kaufman SA, Yoshida H, Spellberg J, et al. Genetic evidence for functional redundancy of platelet/endothelial cell adhesion molecule-1 (PECAM-1): CD31-deficient mice reveal PECAM-1-dependent and PECAM1-independent functions. J Immunol. 1999; 162(5):3022-30

327 Bagi Z, Frangos JA, Yeh JC, White CR, Kaley G, Koller A. PECAM-1 mediates NO-dependent dilation of arterioles to high temporal gradients of shear stress. Arterioscler Thromb Vasc Biol. 2005;25(8):1590-5.

328 Barry AK, Wang N, Leckband DE. Local VEcadherin mechanotransduction triggers long-ranged remodeling of endothelial monolayers. J Cell Sci. 2015;128(7):1341-51.

329 Jin ZG, Ueba H, Tanimoto T, Lungu AO, Frame MD, Berk BC. Ligand-independent activation of vascular endothelial growth factor receptor 2 by fluid shear stress regulates activation of endothelial nitric oxide synthase. Circ Res. 2003;93(4):354-63.

330 Morin-Kensicki EM, Boone BN, Howell M, Stonebraker JR, Teed J, Alb JG, et al. Defects in yolk sac vasculogenesis, chorioallantoic fusion, and embryonic axis elongation in mice with targeted disruption of Yap65. Mol Cell Biol. 2006;26(1):77-87.

331 Dupont S, Morsut L, Aragona M, Enzo E, Giulitti S, Cordenonsi M, et al. Role of YAP/ TAZ in mechanotransduction. Nature. 2011;474(7350):179-83.

332 Nakajima H, Yamamoto K, Agarwala S, Terai K, Fukui H, Fukuhara S, et al. Flow-dependent endothelial YAP regulation contributes to vessel maintenance. Dev Cell. 2017;40(6):523-36.e6.

$333 \mathrm{Xu} \mathrm{J}$, Mathur J, Vessières E, Hammack S, Nonomura K, Favre J, et al. GPR68 senses flow and is essential for vascular physiology. Cell. 2018;173(3):762-75.e16.
334 Betz AL, Firth JA, Goldstein GW. Polarity of the blood-brain barrier: distribution of enzymes between the luminal and antiluminal membranes of brain capillary endothelial cells. Brain Res. 1980;192(1):17-28.

$335 \mathrm{Yu}$ J, Bergaya S, Murata T, Alp IF, Bauer MP, Lin MI, et al. Direct evidence for the role of caveolin-1 and caveolae in mechanotransduction and remodeling of blood vessels. J Clin Invest. 2006;116(5):1284-91.

336 Cheng C, van Haperen R, de Waard M, van Damme LC, Tempel D, Hanemaaijer L, et al. Shear stress affects the intracellular distribution of eNOS: direct demonstration by a novel in vivo technique. Blood. 2005; 106(12):3691-8

337 Straub AC, Billaud M, Johnstone SR, Best AK, Yemen S, Dwyer ST, et al. Compartmentalized connexin 43 s-nitrosylation/denitrosylation regulates heterocellular communication in the vessel wall. Arterioscler Thromb Vasc Biol. 2011;31(2):399-407.

338 Bkaily G, Choufani S, Sader S, Jacques D, d'Orléans-Juste $\mathrm{P}$, Nader M, et al. Activation of sarcolemma and nuclear membranes ET-1 receptors regulates transcellular calcium levels in heart and vascular smooth muscle cells. Can J Physiol Pharmacol. 2003; 81(6):654-62.

339 Garcia J, Patel N, Basehore S, Clyne AM. Fibroblast growth factor-2 binding to heparan sulfate proteoglycans varies with shear stress in flow-adapted cells. Ann Biomed Eng. 2019;47(4):1078-93.

340 Mertens G, Cassiman JJ, Van den Berghe H, Vermylen J, David G. Cell surface heparan sulfate proteoglycans from human vascular endothelial cells. Core protein characterization and antithrombin III binding properties. J Biol Chem. 1992;267(28):20435-43.
341 Marcum JA, Atha DH, Fritze LM, Nawroth $\mathrm{P}$, Stern D, Rosenberg RD. Cloned bovine aortic endothelial cells synthesize anticoagulantly active heparan sulfate proteoglycan. J Biol Chem. 1986;261(16):7507-17.

342 Ruderisch N, Virgintino D, Makrides V, Verrey F. Differential axial localization along the mouse brain vascular tree of luminal sodium-dependent glutamine transporters Snat1 and Snat3. J Cereb Blood Flow Metab. 2011;31(7):1637-47.

343 Cannon RE, Peart JC, Hawkins BT, Campos CR, Miller DS. Targeting blood-brain barrier sphingolipid signaling reduces basal $\mathrm{P}$ glycoprotein activity and improves drug delivery to the brain. Proc Natl Acad Sci U S A. 2012;109(39):15930-5

344 Horvat R, Palade GE. Thrombomodulin and thrombin localization on the vascular endothelium; their internalization and transcytosis by plasmalemmal vesicles. Eur J Cell Biol. 1993;61(2):299-313.

345 Kohler R, Brakemeier S, Kuhn M, Degenhardt C, Buhr H, Pries A, et al. Expression of ryanodine receptor type 3 and TRP channels in endothelial cells: comparison of in situ and cultured human endothelial cells. Cardiovasc Res. 2001;51(1):160-8.

346 Paria BC, Vogel SM, Ahmmed GU, Alamgir $S$, Shroff J, Malik AB, et al. Tumor necrosis factor-alpha-induced TRPC1 expression amplifies store-operated $\mathrm{Ca} 2+$ influx and endothelial permeability. Am J Physiol Lung Cell Mol Physiol. 2004;287(6):L1303-13.

347 Graziani A, Poteser M, Heupel WM, Schleifer H, Krenn M, Drenckhahn D, et al. Cellcell contact formation governs $\mathrm{Ca} 2+$ signaling by TRPC 4 in the vascular endothelium: evidence for a regulatory TRPC4-betacatenin interaction. J Biol Chem. 2010; 285(6):4213-23.

348 Hartmannsgruber V, Heyken WT, Kacik M, Kaistha A, Grgic I, Harteneck C, et al. Arterial response to shear stress critically depends on endothelial TRPV4 expression. PLoS One. 2007;2(9):e827. 